\title{
Repetitive Transcranial Magnetic Stimulation (rTMS) as a Promising Treatment for Craving in Stimulant Drugs and Behavioral Addiction: A Meta-Analysis
}

\author{
Aurélia Gay ${ }^{1,2, *(D)}$, Julien Cabe ${ }^{3}(\mathbb{D})$, Ingrid De Chazeron ${ }^{3} \mathbb{D}$, Céline Lambert $^{4}$, Maxime Defour ${ }^{1}$, \\ Vikesh Bhoowabul ${ }^{1}$, Thomas Charpeaud ${ }^{5}$, Aurore Tremey ${ }^{5}$, Pierre-Michel Llorca ${ }^{3} \mathbb{D}$, Bruno Pereira ${ }^{4} \mathbb{D}$ \\ and Georges Brousse ${ }^{3}$
}

1 University Department of Psychiatry and Addiction, CHU St-Etienne, CEDEX 2, 42055 Saint-Étienne, France; defourmaxime@gmail.com (M.D.); vikesh.bh@gmail.com (V.B.)

2 TAPE Laboratory, EA7423, Jean Monnet University, 42100 Saint-Étienne, France

3 Clermont Auvergne INP, CHU Clermont-Ferrand, CNRS, Institut Pascal, Université Clermont Auvergne, 63000 Clermont-Ferrand, France; jcabe@chu-clermontferrand.fr (J.C.); idechazeron@chu-clermontferrand.fr (I.D.C.); pmllorca@chu-clermontferrand.fr (P.-M.L.); gbrousse@chu-clermontferrand.fr (G.B.)

4 Biostatistics Unit (DRCI), CHU Clermont-Ferrand, 63000 Clermont-Ferrand, France; clamber@@chu-clermontferrand.fr (C.L.); bpereira@chu-clermontferrand.fr (B.P.)

5 Service d'Addictologie et Pathologies Duelles, CHU Clermont-Ferrand, 63000 Clermont-Ferrand, France; tcharpeaud@chu-clermontferrand.fr (T.C.); atremey@chu-clermontferrand.fr (A.T.)

* Correspondence: aurelia.gay@chu-st-etienne.fr; Tel.: +33-04-77828850

Citation: Gay, A.; Cabe, J.; De Chazeron, I.; Lambert, C.; Defour, M.; Bhoowabul, V.; Charpeaud, T.; Tremey, A.; Llorca, P.-M.; Pereira, B.; et al. Repetitive Transcranial Magnetic Stimulation (rTMS) as a Promising Treatment for Craving in Stimulant Drugs and Behavioral Addiction: A Meta-Analysis. J. Clin. Med. 2022, 11, 624. https://doi.org/ $10.3390 /$ jcm 11030624

Academic Editor: Chris Baeken

Received: 22 December 2021

Accepted: 19 January 2022

Published: 26 January 2022

Publisher's Note: MDPI stays neutral with regard to jurisdictional claims in published maps and institutional affiliations.

Copyright: (c) 2022 by the authors Licensee MDPI, Basel, Switzerland. This article is an open access article distributed under the terms and conditions of the Creative Commons Attribution (CC BY) license (https:// creativecommons.org/licenses/by/ $4.0 /)$.

\begin{abstract}
Addiction is a mental disorder with limited available treatment options. The therapeutic potential of repetitive transcranial magnetic stimulation (rTMS) on it, by targeting craving in particular, has been explored with heterogenous results. This meta-analysis uses updated evidence to assess overall rTMS efficacy on craving, differential effects between addiction types clustered into three groups (depressant (alcohol, cannabis, opiate), stimulant (nicotine, cocaine, methamphetamine), and behavioral addiction (gambling, eating disorder)), and stimulation settings. Studies on substance use, gambling, and eating disorders are included, with unrestricted stimulation settings, by searching the PubMed, Embase, PsycINFO, and Cochrane databases up to 30 April 2020. A total of 34 eligible studies (42 units of analysis) were identified. Because of highly significant heterogeneity in primary results, a sensitivity analysis was performed on a remaining sample of 26 studies (30 units of analysis). Analyses performed using random effects model revealed a small effect size favoring active rTMS over shamTMS stimulation in the reduction in craving. We found a significant difference between addiction types, with a persistent small effect only for stimulant and behavioral groups. In these groups we found no difference between the different combinations of target and frequency of stimulation, but a significant correlation between number of sessions and craving reduction. In conclusion, efficacy of rTMS on craving in stimulant and behavioral addiction was highlighted, but recommendations on optimal stimulation settings and its clinical application await further research.
\end{abstract}

Keywords: addiction; craving; dorsolateral prefrontal cortex; eating disorder; gambling disorder; transcranial magnetic stimulation; substance use disorder

\section{Introduction}

Drug addiction can be defined as a chronically relapsing disorder, characterized by compulsion to seek and take a drug, loss of control in limiting its intake, and emergence of a negative emotional state (e.g., dysphoria, anxiety, irritability) when access to the drug is prevented [1]. In 2013, DSM-5 [2] defined substance use disorders (SUDs) over a range from mild to moderate to severe, with the severity of an addiction depending on how many of the established 11 specific diagnosis criteria apply. The latest version of these diagnostic 
criteria also includes "non-substance-related disorders", defined as addictive disorders not involving ingestion of a psychoactive substance. Currently, gambling disorder in DSM-5 [2] and gaming disorder in the 11th Revision of the International Classification of Diseases (ICD-11) [3] are the only conditions included in international classifications. In an extended definition of behavioral addiction (BA), eating disorders (EDs) (anorexia nervosa, bulimia nervosa, and binge eating disorder) have also been deemed forms of addiction [4,5].

Addiction is a chronic disorder that is very costly to affected patients and to society in general [6]. According to the World Health Organization (WHO), the use of tobacco, alcohol, and illicit drugs contributes significantly to the global burden of disease, is implicated in over $12 \%$ of mortality worldwide, and is the leading cause of preventable death [7]. Behavioral addictions are also pervasive and disabling. Gambling disorder has adverse impacts such as disrupted family and marital relationships, financial difficulties, mental and physical health problems, and diminished life fulfillment [8]. Bulimia nervosa is associated with an increased mortality, especially by suicide [9], and EDs affect the quality of life of both patients and their families, and individuals with these disorders have particularly high rates of health service use $[10,11]$.

To date, available treatment options for addictive behaviors remain limited, and longterm success rates are poor [12]. Meta-analytical studies suggest that across substances, combined pharmacological treatment and behavioral intervention may increase clinical success and ameliorate clinical attendance and patient retention [13-15]. For pharmacotherapy, many different substances have been tested [16]. However, the results of these trials have fallen short of expectations [17-20], not all addictive disorders have empirically validated treatments, and available pharmacotherapies do not meet overall clinical requirements. There is therefore a need to explore novel approaches to treating substance-related and addictive disorders. Craving is one treatment target that can be usefully addressed.

Craving is a core clinical symptom of addiction. It has received considerable research attention for several decades [21]. Craving is defined as a pressing, urgent, and irrepressible desire to give way to an addictive behavior, motivated by internal and external cues, resulting in loss of control in most cases [22]. It also includes the expectation of previously experienced effects of a psychoactive drug, whether these are its positive effects or the relief of its negative effects, or both [23]. This key symptom has been extensively studied in drug addiction and eating disorders [24,25] and in other behavioral addiction such as gambling disorder [26]. There are currently various experimental measurements of this state: standardized questionnaires, visual analogue scale (VAS), and non-verbal physiological measures $[27,28]$. Drug craving is considered an important risk factor for relapse in patients with addictive disorder, as shown for example in alcohol [29,30], cocaine [31,32], or gambling [33], and alleviating craving has been considered a beneficial target to curb addictive behavior [28].

Neuroimaging studies in humans have shown that craving is underpinned by activation of the reward and motivation circuits. These studies show that the main structures involved are the nucleus accumbens, dorsal striatum, amygdala, hippocampus, insula, and the prefrontal cortex (PFC), including dorsolateral prefrontal cortex (DLPFC), anterior cingulate cortex (ACC), and medial orbitofrontal cortex (OFC) [34-38].

Neurobiologically, addiction is associated with disturbances in the brain's reward, stress, and executive function systems $[1,39,40]$. Notably, repetition of intake and binges are associated with the replication of a dopamine-firing pattern through the mesocorticolimbic pathways, leading to the development of incentive salience and drug-seeking habits [41] and to neuroadaptations resulting in decreased dopamine secretion [42]. The craving and deficits in executive function, in the so-called preoccupation/anticipation stage, could involve the dysregulation of key afferent projections from the PFC and insula to the basal ganglia and extended amygdala. This neurobiological model of addiction provides an approach to medication development. The therapeutic potential of brain stimulation techniques has been suggested [1]. 
Repetitive transcranial magnetic stimulation (rTMS) is a noninvasive brain stimulation technique that leads to cerebral neuromodulation through a modification of cortical excitability, of blood flow to the area [43], of the frequency of neuronal discharge [44], and of the release of neurotransmitters such as dopamine $[45,46]$. In addition to its cortical action, TMS is claimed to act remotely on deeper structures, via brain circuits and interhemispheric connections [47-49]. An alternative to the conventional figure-of-eight rTMS coils is the so-called H-coil system [50], developed to reach deeper brain regions [51] and whose derived therapeutic application has been called "deep transcranial magnetic stimulation" (dTMS) [52]. High-frequency (HF) stimulation $(\geq 5 \mathrm{~Hz})$ is considered to have excitatory effects on the targeted cortical excitability, whereas low-frequency (LF) stimulation $(\leq 1 \mathrm{~Hz})$ is reported to have inhibitory effects [53]. These effects can outlast the stimulation period. Following these "classic" protocols, new TMS paradigms have been developed such as "theta burst stimulation" (TBS), delivered continuously (cTBS) (inhibitory effects) or intermittently (iTBS) (excitatory effects) [54]. Numerous studies have shown that rTMS produces significant clinical effects in patients with various neurological and psychiatric disorders [55]. One line of research that has emerged since the early 2000s examines the efficacy of rTMS on addiction and related disorders by targeting craving in particular. Transcranial direct current stimulation (tDCS) is another non-invasive brain stimulation method that generates a low intensity electric field between two electrodes, increasing neuronal excitability under the anodal but decreasing it under the cathodal electrode [56]. tDCS is also currently being investigated as a potential treatment for SUDs with encouraging results, but we chose to focus on rTMS in our work [57].

As regards targets, particular attention has been paid to the DLPFC in neuromodulation studies in addiction. First, its stimulation could increase dopamine excretion in mesolimbic and mesostriatal pathways, through its interconnection with the ventral tegmental area (VTA) and ventral striatum [46,58,59], and thus could redress drug-induced dopaminergic dysfunction [60]. Second, DLPFC repetitive stimulation could correct diminished functioning of the prefrontal cortex including DLPFC, ventromedial prefrontal cortex (VMPFC), and ACC described in imaging studies in addictive disorders [61], and presumably underlining diminished cognitive and behavioral control, and a higher tendency to cue-induced relapse [62,63]. More recently, other approaches have been proposed, such as inhibition of the medial PFC to decrease striatal and insula activity, thereby weakening drug-related craving and attenuating frontostriatal reactivity to substance-related cues [64].

Eight meta-analyses [24,57,65-70] have focused on neuromodulation and addictive disorders but with various inclusion criteria and some differences in conclusions, notably concerning differences in efficacy according to addiction type. On the one hand, previous studies that included several addiction types found no difference as regards indication, but some found differences for stimulation settings. Jansen et al. (2013) was the first to show that stimulation (including also tDCS studies; 17 studies overall) on the DLPFC can decrease craving in patients with SUD and food addiction, without significant differences between various substances of abuse or between substances of abuse and food [24]. These results were replicated by Song et al. (2018), who included 44 studies focusing on DLPFC activation [57]. Two other meta-analyses, limited to SUD, pointed to differences only for stimulation settings. Enokibara et al. (2016) found active rTMS stimulation to outperform placebo only for right DLPFC stimulation [65], contrary to Zhang et al. (2019), who found that only excitatory rTMS of the left DLPFC significantly reduced craving [70]. On the other hand, four other meta-analyses, which restricted their scope to certain types of addiction, failed to replicate positive results for all of them: Maiti et al. (2016) focused on HF stimulation in alcohol and nicotine use disorder [68], Lowe et al. (2017) on food craving [66], including rTMS and tDCS studies, Ma et al. (2019) on psychostimulants (cocaine, amphetamine, and methamphetamine) [67], and Mostafavi et al. (2020) on alcohol [69]. These studies supported rTMS efficacy on craving in nicotine use disorder [68], psychostimulants [67], and food [66], but not in alcohol use disorder [68,69]. 
Studies so far thus tend to support rTMS as a novel, safe anti-craving therapeutic intervention, but results are still controversial, in particular concerning preferred indication, with heterogenous results according to addiction type. Additionally, behavioral addictions were not systematically included and were restricted to eating disorder/food addiction. Moreover, the studies are characterized by a wide variation in relation to the rTMS intervention protocols (target and frequency of stimulation, number of pulses per session, number of sessions), and the optimal treatment settings remain to be specified [49,71]. The primary aim of our meta-analysis was thus to evaluate the updated evidence regarding the effects of rTMS compared with sham stimulation (shamTMS) on craving in substance-related and addictive disorders, including all behavioral addiction, and to better define indication according to addiction type. Second, we aimed to better define optimal stimulation settings as regards target (side and location) combined with frequency of stimulation (high versus low) and method for locating it (use of neuronavigation or not), number of sessions, and number of pulses (per session and total).

\section{Materials and Methods}

This meta-analysis was conducted and reported in conformance with the Preferred Reporting Items for Systematic Reviews and Meta-Analysis (PRISMA) statement [72]. The Cochrane handbook was used as a methodological reference [73]. We registered the protocol in the International Prospective Register of Ongoing Systematic Reviews (systematic review registration-PROSPERO 2020: CRD42020114671).

\subsection{Search Strategy}

We identified articles for inclusion in this review by searching the PubMed, Embase, PsycINFO, and Cochrane databases up to 30 April 2020, limiting our search to articles published in English and German (one article). Our enquiry was constructed following the PICO method (Population, Intervention, Comparison, Outcome). The key items we used in our search were as follows: "P", substance-related and addictive disorders/substance use disorder/addiction to drugs, alcohol and nicotine/dependence/substance abuse/eating disorder/gambling disorder/behavioral addiction; "I", rTMS/transcranial magnetic stimulation/deep TMS); “C”, shamTMS/placebo/control group; and “ $\mathrm{O}$ ”, craving.

\subsection{Inclusion Criteria for the Selection of Studies}

To control for the placebo effect, only randomized controlled trials (RCTs) and controlled clinical trials (CCTs) were included in our meta-analysis. Craving reduction had to be an outcome measure, either primary or secondary.

Concerning type of participants, we included studies examining adult human subjects of either sex with a diagnosis of substance-related and addictive disorders, including behavioral addictions, meeting DSM- 5 or former DSM-IV-TR substance abuse or dependence or ICD-10 criteria. By equating eating disorders with behavioral addiction, we included in our meta-analysis studies examining subjects with anorexia nervosa (AN), bulimia nervosa $(\mathrm{BN})$, and binge eating disorder (BED), but not healthy subjects experiencing strong food craving. As comorbidity is very common in addictive disorders, we did not exclude studies of subjects with psychiatric comorbidity.

Studies had to evaluate the effect of rTMS (figure-of-eight or double-cone coil) or deep TMS (dTMS), irrespective of stimulation settings (including theta burst stimulation) and method used to localize the target. rTMS/dTMS could be performed alone or as an add-on to usual pharmacological treatment or psychotherapy. The outcome measure was change in craving after last rTMS session from baseline (pre rTMS), measured by different craving assessment tools.

The studies included were not restricted by date of publication, craving assessment tool, number of stimulation sessions, or site of stimulation. Studies evaluating tDCS effect were excluded from our meta-analysis. 


\subsection{Study Selection and Data Collection}

The relevant studies were selected in a stepwise manner. A manual search and screening of the bibliography of the selected studies were performed in addition to the computerized screening. Duplicate searches were eliminated. First, all studies were screened based on title and abstract. Second, the full texts of all the studies from this selection were read, and studies were included in the meta-analyses if all inclusion criteria, determined before the literature search was performed, were met. Three authors independently performed study selection (A.G., G.B., and J.C.) with disagreements resolved by discussion in consultation with the statistics advisor (B.P.), referring to guidelines published by Cochrane Collaboration [73]. Extracted data for meta-analysis comprised study design, participants, substance or behavior involved, site of stimulation, method for localization, frequency of stimulation, number of stimulation sessions, total pulse per session, and standardized effect sizes for the effect of stimulation on craving levels. Graphically reported data were extracted from the figures by one author (A.G.) and one statistics advisor (C.L. or B.P.) In cases of disagreement, a third extraction was made by I.D.C. or J.C. For descriptive purposes, Supplementary Data were collected: motor threshold, assessment time-points, and outcome measures other than craving.

"Study" was considered as unit of design instead of the "unit for analyses". Studies in which two tools were used to assess craving, or in which two or more stimulation settings were compared, were considered separately as two "units of analysis". If studies compared the effect of rTMS on craving using exposure to neutral and addiction-related stimuli, we selected cue-induced craving only, as this is considered as the most ecological measure of craving [71,74]. When reported data were insufficient for data analysis, authors were contacted to retrieve the data.

\subsection{Data Analysis}

Baseline characteristics are summarized for each study sample and reported as mean and standard deviation (SD) or median and inter-quartile range, and number (\%) for continuous and categorical variables, respectively. The meta-analysis took account of between- and within-study variability. To address the non-independence of data due to study effect, random effects models [75] were preferred to the usual statistical tests to assess the standardized paired mean differences (SMDs) of craving and their 95\% confidence intervals. Hedge's $g$ SMDs were estimated to assess the difference between baseline (T0) and last follow-up (T1) evaluation in craving levels, between active and shamTMS stimulation. The analyses were performed (i) on post-session craving change when this was reported in studies or (ii) on the calculation of craving change from baseline (T1-T0) with standard deviation of the paired mean difference between $\mathrm{T} 0$ and $\mathrm{T} 1$ estimated using the formula: $\left[\mathrm{SD}^{2} \mathrm{~T} 0+\mathrm{SD}^{2} \mathrm{~T} 1-\left(2 \times 0.5 \times \mathrm{SD}_{\mathrm{T} 0} \times \mathrm{SD}_{\mathrm{T} 1}\right)\right]$. Means and standard deviations were compiled when available or were estimated when median and interquartile range were reported [76]. When standard deviation was not available, an estimation according to available standard deviations (for other studies) was calculated. The cross-over nature of the within-subject study was ignored, and the sample was treated as two separate groups. This method provides a more conservative estimate of the effect size and allows comparison of betweenand within-subject designs. Hedge's $g$ is considered to be a conservative estimate, which is useful for studies with small sample sizes, and the results may be interpreted as reflecting a small $(g=0.2-0.5)$, medium $(g=0.5-0.8)$, or large effect $(g>0.8)$ [77].

Heterogeneity in the study results was assessed by forest plots and the $I^{2}$ statistic, the most common metric for measuring the magnitude of between-study heterogeneity, and one which is easily interpretable. $I^{2}$ values range between 0 and $100 \%$ and are typically considered low for $<25 \%$, moderate for $25-50 \%$, and high for $>50 \%$ [78]. Publication bias was assessed by funnel plots, confidence intervals, and with the Egger regression test as a formal statistical test.

To check the robustness of the results, sensitivity analyses were performed, excluding studies that were not evenly distributed around the base of the funnel plots. Furthermore, 
as dTMS can be considered as a different technique of rTMS, a sensitivity analysis without the studies using these techniques was also conducted.

Meta-regression and subgroup analyses were then performed to compare the influence of the different addiction types on effect size for studies retained after sensitivity analyses. Because of the various addiction types included, we opted to categorize them into three subgroups, based on their expected effect for SUD: depressant (alcohol, cannabis, and opiates) or stimulant (nicotine, cocaine, methamphetamine), and individualizing the behavioral group (eating and gambling disorder). As study design (crossover versus parallel design) may mediate stimulation effects [79], meta-regression was performed to identify the potential influence of independent variables on SMD. For an addiction type for which a significant effect was highlighted, the influence of target (location and side) combined with stimulation setting (HF/LF), method used for target localization (neuronavigation/other methods), and number of sessions (single versus multiple) were assessed. The relationships between number of sessions, number of pulses per session, total number of pulses, and craving change from baseline only in the rTMS group, were also evaluated (Table A1 in Appendix A).

Statistical analyses used Stata software (version 15, StataCorp, College Station, TX, USA). Two-sided type I error was fixed at 5\%.

\section{Results}

\subsection{Search Results}

After screening on PICO criteria, the initial literature search identified 132 potentially eligible studies for assessment and inclusion in the meta-analysis. In addition to these studies, review articles were thoroughly read to ensure no study was missed. The PRISMA flow diagram depicts the full selection process (Figure 1). For diverse reasons, 98 studies were excluded at this stage-namely, case reports or series; studies not mentioning craving as an outcome measure; non-controlled trials (no shamTMS stimulation group, of which three comparing different stimulation sites, one comparing new population with a subsample of another study, and three with standard drug treatment as a control group, without a shamTMS coil); ancillary studies from studies included in the meta-analysis, presenting imaging, biological, or cognitive data; studies for which only conference abstracts were available and with too many missing data or too much uncertainty concerning study overlap and with no author information; and trials in subjects with high food craving without ED. In eight studies, detailed statistical data were not sufficient to calculate a standardized mean difference. The corresponding authors were contacted by e-mail and asked to provide the data necessary for the meta-analysis; only two authors responded, despite reminders. Two authors could not be contacted because their e-mail addresses were incorrect or not provided in the article. Thus, 34 studies were finally included in the meta-analysis (42 units of analysis) (see in Appendix A Table A1 for descriptive data of included studies and their main results, including other outcome measures than craving).

In 11 studies, data were extracted totally or partly from figures [80-90].

Of the 34 studies included in the meta-analysis, 1 concerned both alcohol and cocaine, 10 alcohol, 8 nicotine, 1 cannabis, 1 cocaine, 6 methamphetamine, 1 opiate, 3 eating disorder (2 BN or "eating disorder not otherwise specified"-bulimic type (EDNOS-BN), $1 \mathrm{AN}$ ), and 3 gambling disorder (Table A1 in Appendix A).

dTMS was used in three studies in the meta-analysis [86,91,92].

The quality assessment of the studies included in the meta-analysis is presented through a risk of bias graph in Figure 2, showing the proportion of studies with each judgment ("low risk", "some concerns", "high risk" of bias) for each risk of bias item. Detailed risk of bias for each study is presented in Supplementary Materials (Figure S1). 


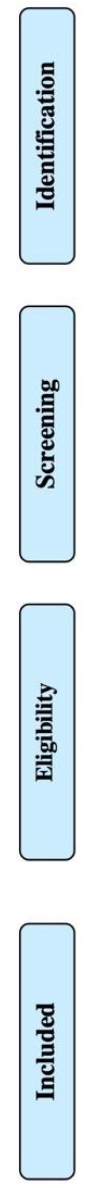

Records identified through database searching: 1735

No additional record identified through other sources (including comprehensive reading of review articles)

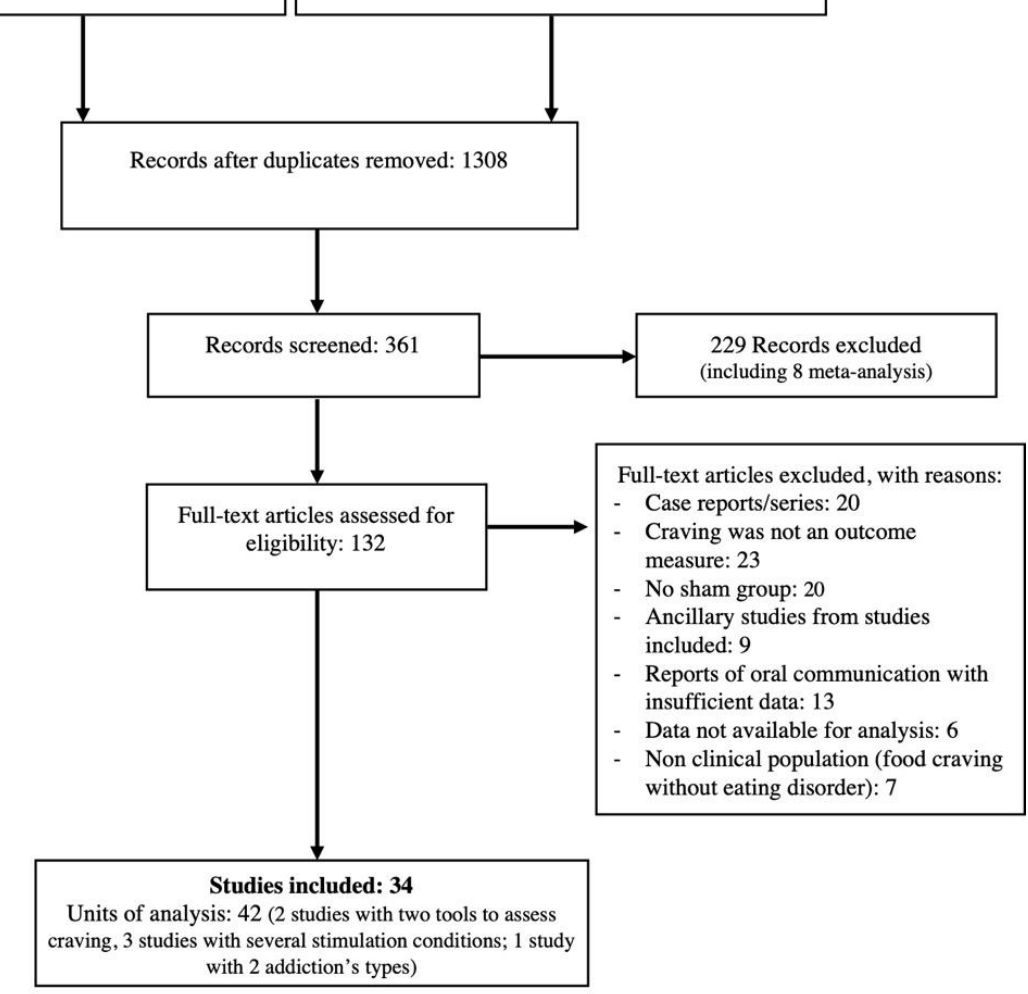

Figure 1. PRISMA flow diagram for the study selection process.

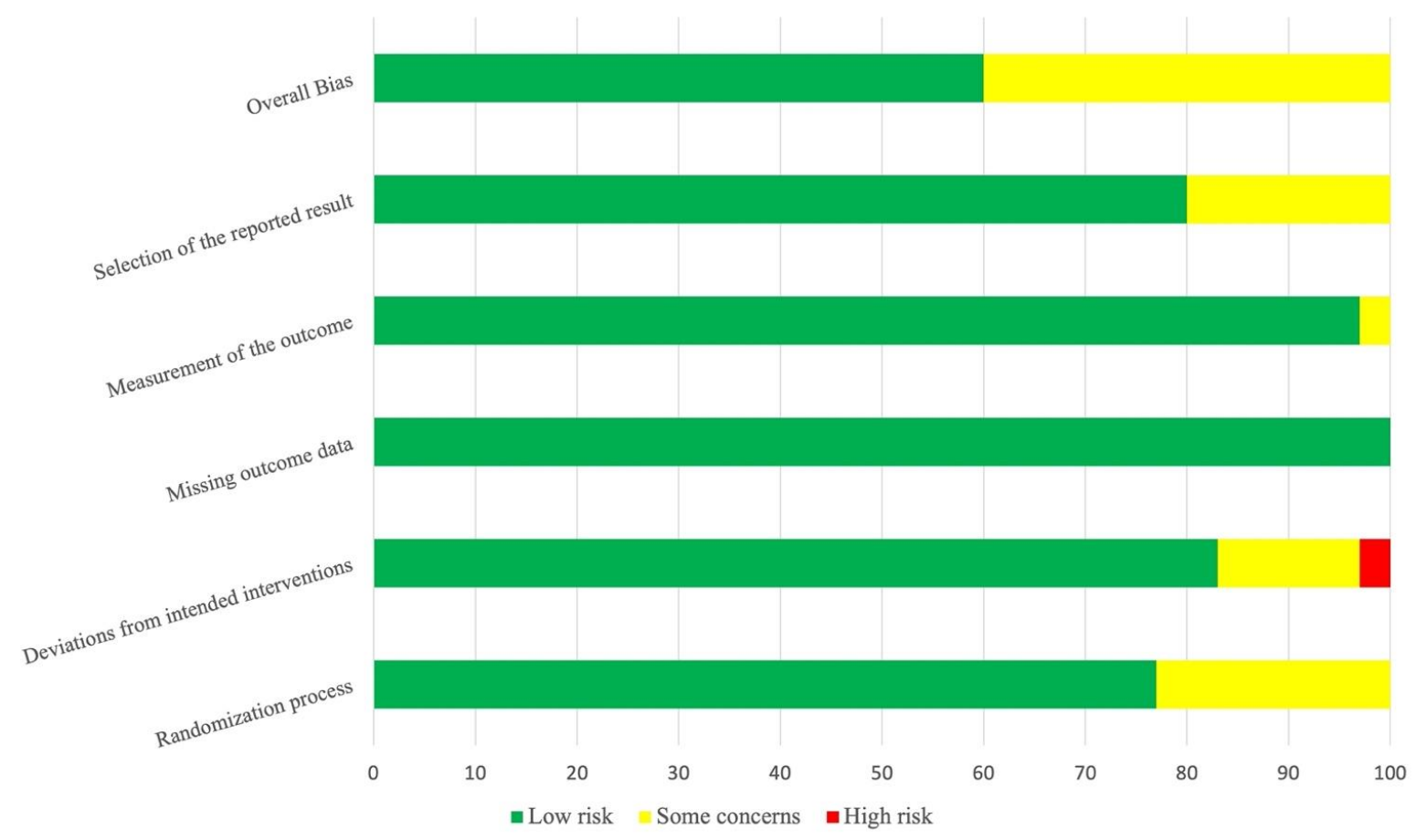

Figure 2. Risk summary of bias. For each risk of bias item, proportion of studies included in the meta-analysis $(k=42)$ with low, high, or unclear risk according to authors' judgments. 


\subsection{Main Results}

3.2.1. Overall Effect of rTMS and Sensitivity Analysis

This analysis revealed a pooled standardized effect size (Hedge's $g$ ) of -0.445 (95\% CI: $-0.667,-0.224)$, indicating an overall small effect size favoring active stimulation over shamTMS stimulation $(z=3.94, p<0.001)$ (Figure 3). The test for heterogeneity was significant $\left(I^{2}=75.3 \%\right)$. The Egger regression test was not significant for overall studies initially included $(k=42, t=-1.38, p=0.175)$.

$$
\text { Study }
$$

$$
\text { ID }
$$

$\operatorname{SMD}(95 \% \mathrm{Cl})$

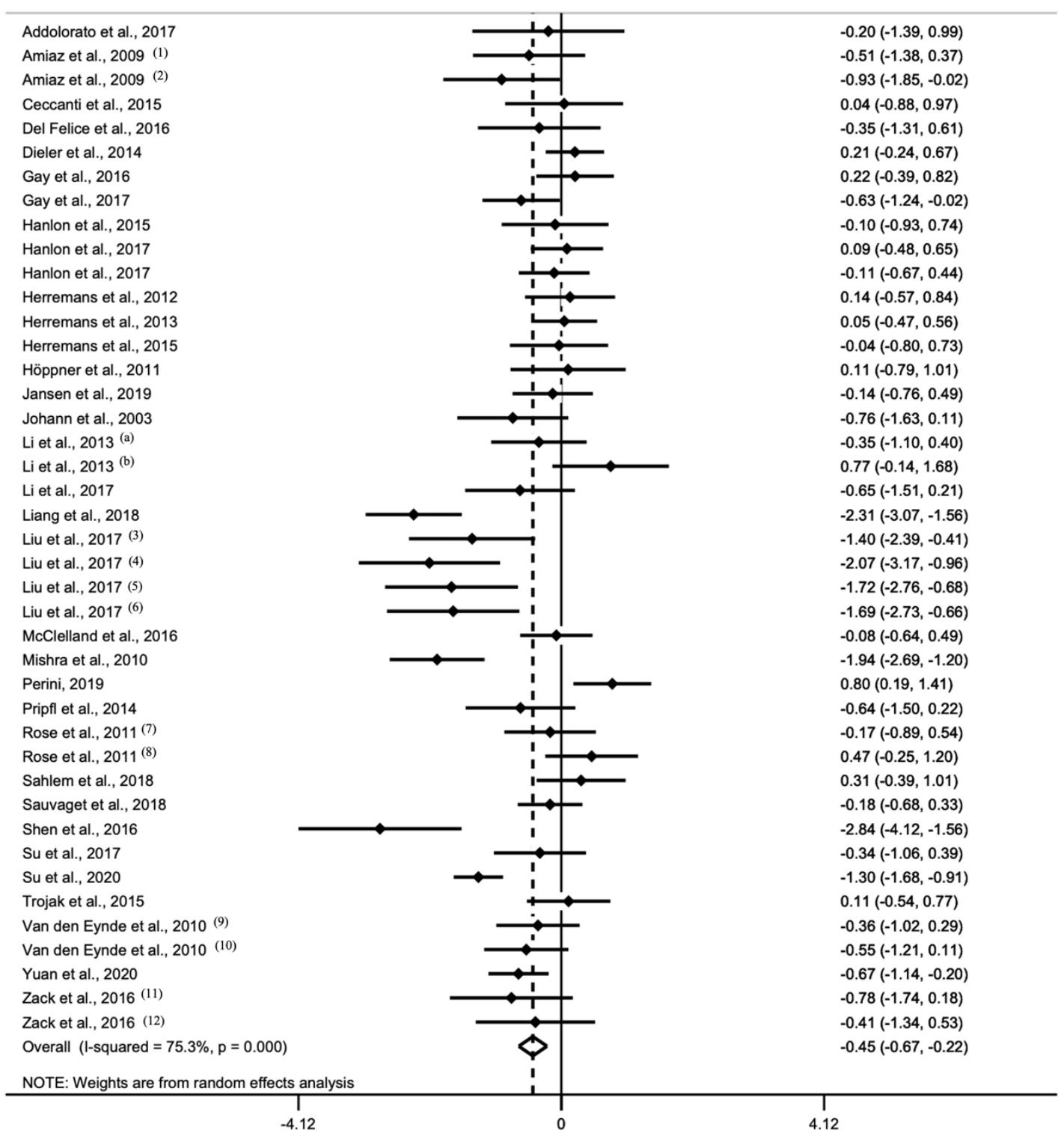

\section{FAVORS rTMS}

FAVORS shamTMS

Figure 3. Forest plot for all included studies pooled together using random effects model (34 studies, 42 units of analysis) [80-113]. Heterogeneity: $\mathrm{Q}=165.67, \mathrm{df}=41, p<0.001, I^{2}=75.3 \%$. (1), craving evaluated by Visual Analog Scale (VAS); (2), craving evaluated by sTCQ; (3), high frequency left DLPFC stimulation; (4), high frequency right DLPFC stimulation; (5), low frequency left DLPFC stimulation; (6), low frequency right DLPFC stimulation; (7), low frequency stimulation; (8), high frequency stimulation; (9), craving evaluated by VAS; (10), craving evaluated by FCQ-s; (11), high frequency MPFC stimulation; (12), low frequency right DLPFC stimulation; (a), [103]; (b), [89]. 
Based on visual inspection of a funnel plot (Figure 4), we excluded 12 units of analysis and performed sensitivity analyses on the remaining units of analysis $(k=30)$. The test for heterogeneity was no longer significant $\left(I^{2}=0 \%\right)$. This analysis revealed a pooled standardized effect size of $g=-0.228$ (95\% CI: $-0.355,-0.102)$, indicating an overall small effect size favoring active stimulation over shamTMS stimulation $(z=3.53, p<0.001)$.

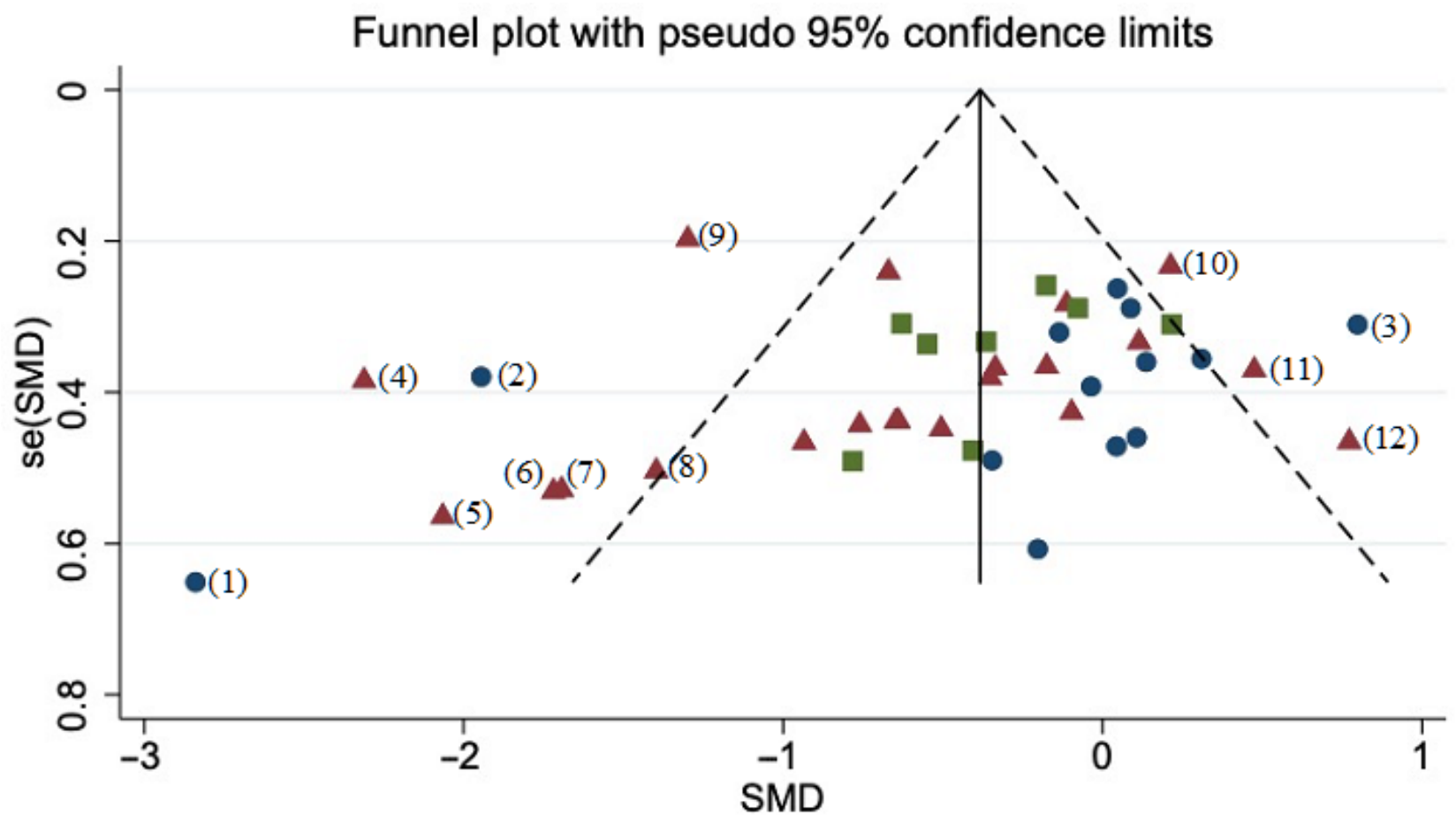

\begin{tabular}{|c|c|c|c|}
\hline & 1:DEPRESSANT & $\Delta$ & 2:STIMULANT \\
\hline-- & 3:BEHAVIORAL & $\underline{-----}$ & Lower Cl \\
\hline
\end{tabular}

Figure 4. Funnel plot for publication bias of the included studies (42 units of analysis). (CI, confidence interval; SE, standard error; SMD, standard mean difference). Type of addiction: depressant (alcohol, cannabis, opiate); stimulant (nicotine, cocaine, methamphetamine); behavioral (eating disorder, gambling disorder). Outlier studies excluded from sensitivity analysis: (1), [108]; (2), [106]; (3), [86]; (4), [84]; (5-8), [85]; (9), [110]; (10), [95]; (11), high frequency arm from [88]; (12), [89].

After excluding outlier studies, the funnel plot was almost symmetrical, indicating minimal publication bias across the studies. Sensitivity analysis after excluding dTMS studies showed no impact on overall rTMS effect. Further analyses were performed on our restricted sample after sensitivity analysis $(k=30)$.

\subsubsection{Analyses between Addiction Type Groups}

As stated above, given the various addiction types included (eight different types), we opted to cluster them into three groups: depressant, stimulant, and behavioral (Figure 5 and Table A1 in Appendix A). 
Study

ID

$\operatorname{SMD}(95 \% \mathrm{Cl})$

1:DEPRESSANT

Addolorato et al., 2017

Ceccanti et al., 2015

Del Felice et al., 2016

Hanlon et al., 2017

Herremans et al., 2012

Herremans et al., 2013

Herremans et al., 2015

Höppner et al., 2011

Jansen et al., 2019

Sahlem et al., 2018

Subtotal $(I-$ squared $=0.0 \%, p=0.994)$

\section{2:STIMULANT}

Amiaz et al., 2009 (1)

Amiaz et al., 2009 (2)

Hanlon et al., 2015

Hanlon et al., 2017

Johann et al., 2003

Li et al., $2013^{(a)}$

Li et al., 2017

Pripfl et al., 2014

Rose et al., $2011^{\text {(3) }}$

Su et al., 2017

Trojak et al., 2015

Yuan et al., 2020

Subtotal (I-squared $=0.0 \%, p=0.692$ )

3:BEHAVIORAL

Gay et al., 2016

Gay et al., 2017

McClelland et al., 2016

Sauvaget et al., 2018

Van den Eynde et al., $2010^{(4)}$

Van den Eynde et al., $2010^{(5)}$

Zack et al., 2016 (6)

Zack et al., 2016 (7)

Subtotal (I-squared $=0.0 \%, p=0.505$ )

Overall (I-squared $=0.0 \%, p=0.720$ )

NOTE: Weights are from random effects analysis

$$
-1.85
$$

FAVORS rTMS

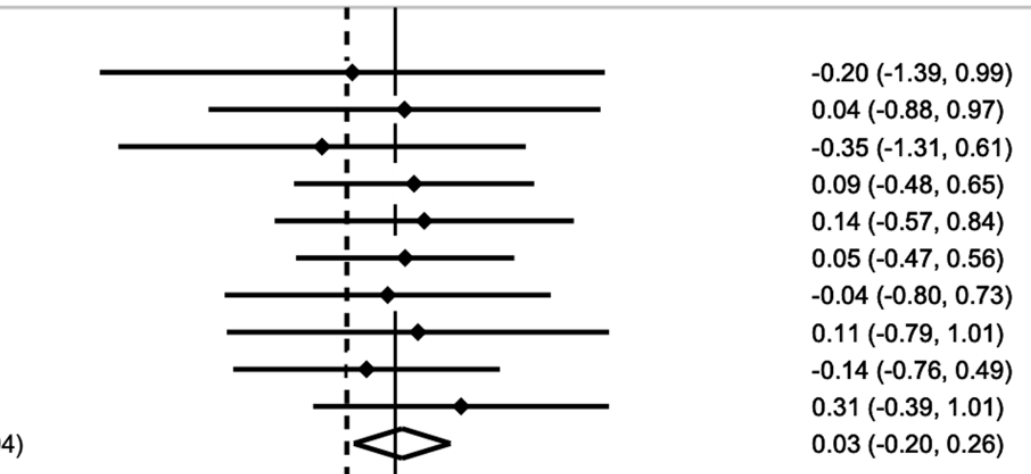

$-0.93(-1.85,-0.02)$

$-0.51(-1.38,0.37)$

$-0.10(-0.93,0.74)$

$-0.11(-0.67,0.44)$

$-0.76(-1.63,0.11)$

$-0.35(-1.10,0.40)$

$-0.65(-1.51,0.21)$

$-0.64(-1.50,0.22)$

$-0.17(-0.89,0.54)$

$-0.34(-1.06,0.39)$

$0.11(-0.54,0.77)$

$-0.67(-1.14,-0.20)$

$-0.40(-0.60,-0.19)$

$0.22(-0.39,0.82)$

$-0.63(-1.24,-0.02)$

$-0.08(-0.64,0.49)$

$-0.18(-0.68,0.33)$

$-0.55(-1.21,0.11)$

$-0.36(-1.02,0.29)$

$-0.78(-1.74,0.18)$

$-0.41(-1.34,0.53)$

$-0.28(-0.51,-0.06)$

$-0.23(-0.35,-0.10)$

Figure 5. Forest plot for the subgroup analysis by addiction type's group (depressant: alcohol, cannabis, opiate [81,82,91,92,94,98-101,107]; stimulant: nicotine, cocaine, methamphetamine [80,87,88,90,93,98,102-104,109,111]; and behavioral: eating disorder, gambling disorder $[89,96,97,105,112,113]$ ) using random effects model (without excluded studies, 30 units of analysis). Heterogeneity: $\mathrm{Q}=24.18, \mathrm{df}=29, p=0.72, I^{2}=0 \%$. Test for overall effect: Hedge's $g=-0.228$ (95\% CI: $-0.355,-0.102), z=3.53, p<0.001$. (1), craving evaluated by Visual Analog Scale (VAS); (2), craving evaluated by sTCQ; (3), low frequency stimulation; (4), craving evaluated by VAS; (5), craving evaluated by FCQ-s; (6), high frequency MPFC stimulation; (7), low frequency right DLPFC stimulation; (a), [103].

Meta-regression analyses showed a significant difference on SMD between addiction groups $(\mathrm{F}(2,27)=3.92, p=0.032)$ with a significant difference only between depressant and stimulant groups $(t=-2.74, p=0.011)$. A pooled standardized effect size of $g=0.032(95 \%$ 
CI: $-0.195,0.259)$ was estimated for the depressant group, indicating no effect of active versus shamTMS stimulation $(z=0.28, p=0.781)$. A pooled standardized effect size of $g=-0.396$ (95\% CI: $-0.601,-0.191)$ was observed for the stimulant group and of -0.284 (95\% CI: $-0.511,-0.056)$ for behavioral addiction, indicating for both a small effect size favoring active over shamTMS stimulation (respectively, $z=3.78, p<0.001$ and $z=2.45$, $p=0.014$ ) (Figure 5).

For descriptive purposes, results by addiction type are presented in Figure 6. Subgroup analyses showed a significant effect only for nicotine, methamphetamine, and gambling disorder, indicating for all a small effect size favoring active over shamTMS stimulation, except for methamphetamine, with a medium effect size (nicotine: $z=2.88, p=0.004$; gambling: $z=2.44, p=0.015$; methamphetamine: $z=2.83, p=0.005)$.

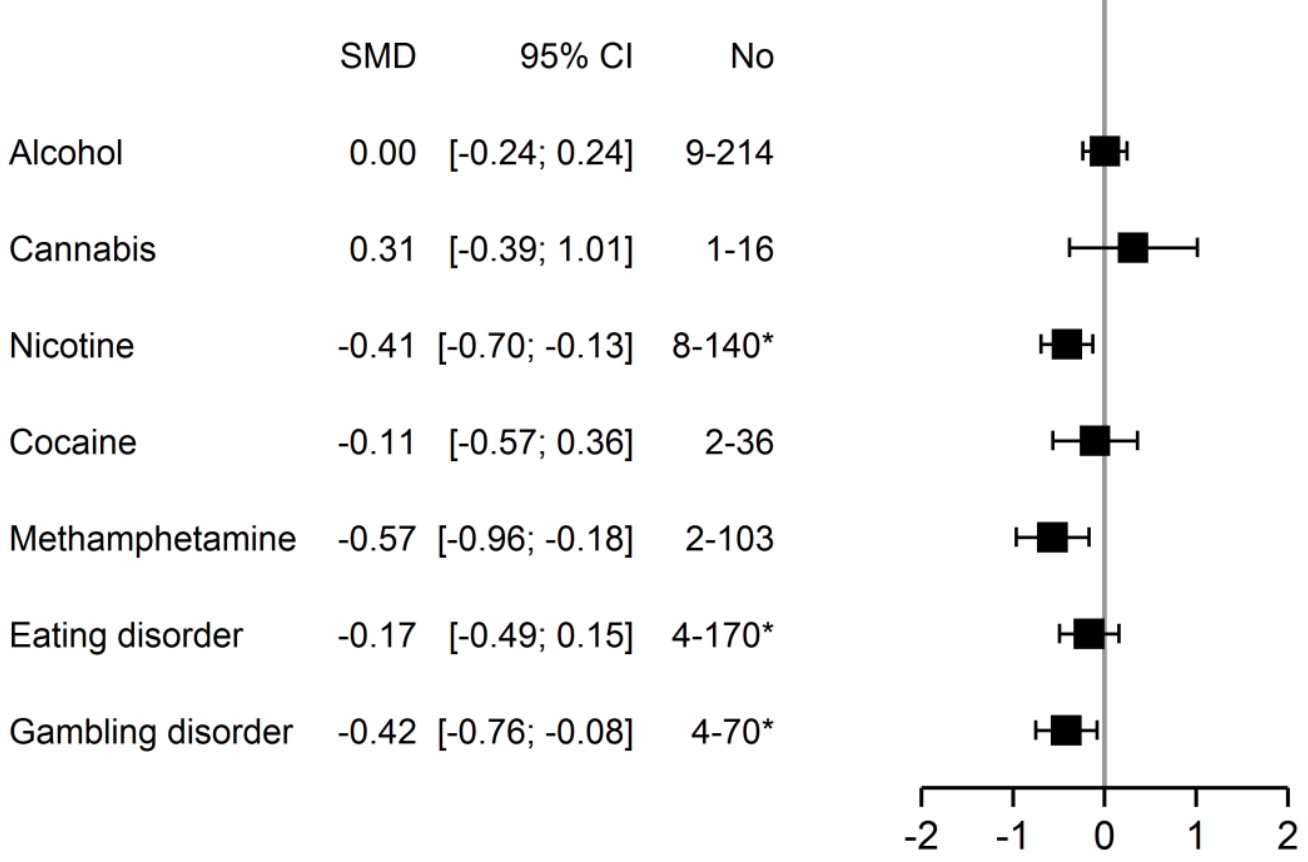

Figure 6. Subgroup analysis by addiction type using random effects model (without excluded studies, 30 units of analysis). (CI, confidence interval; No, number of units of analysis-number of patients included; SMD, standard mean difference). * Indicating difference between number of units of analysis and number of studies, with the following data: nicotine, 7-119; eating disorder, 3-133; gambling disorder, 3-61.

\subsection{Analysis of Stimulation Settings}

Analyses of stimulation settings are presented only for stimulant and behavioral groups, pooled together $(k=20)$, as no significant effect was observed in the depressant group.

We found no significant difference between crossover and parallel studies $(t=0.34$, $p=0.736)$.

As regards stimulation settings, meta-regression analyses showed no significant difference on SMD between method of target localization (use of neuronavigation or not) $(t=0.14, p=0.894)$ and number of sessions (single versus multiple) $(t=0.16, p=0.875)$. Meta-regression between different combinations of target and frequency could not be carried out because numbers of studies per group were too small. Subgroup analyses are presented for their descriptive interest in Table 1.

In these two groups pooled together (stimulant and behavioral addictions), only in the rTMS group, we found no correlation between craving change from baseline and number of pulses per session $(\mathrm{r}=-0.037, p=0.881$ ) but found a marginal association with the 
total number of pulses $(r=-0.454, p=0.059)$ and a significant correlation between craving change from baseline and number of session $(\mathrm{r}=-0.45, p=0.046)$.

Table 1. Subgroup analysis on stimulation settings (target and frequency, method of localization, number of sessions (single versus multiple)) for stimulant (nicotine, cocaine, methamphetamine) and behavioral (eating disorder, gambling disorder) groups $(k=20)$.

\begin{tabular}{|c|c|c|c|c|c|c|c|}
\hline & \multirow[b]{2}{*}{$k^{*}$} & \multicolumn{3}{|c|}{ Effect Size } & \multicolumn{3}{|c|}{ Heterogeneity } \\
\hline & & $\begin{array}{c}\text { Hedge's } g \\
\text { (Random Effect) }\end{array}$ & CI 95\% & Z-Statistic & $p$ & $p$ & $I^{2}$ \\
\hline \multicolumn{8}{|l|}{ Target and frequency } \\
\hline HF Left DLPFC & 12 & -0.396 & $\begin{array}{l}-0.603 \\
-0.190\end{array}$ & 3.76 & $<0.001$ & 0.656 & 0 \\
\hline LF Left DLPFC & 1 & -0.670 & $\begin{array}{l}-1.142 \\
-0.198\end{array}$ & 2.78 & $<0.001$ & - & - \\
\hline LF Right DLPFC & 3 & -0.120 & $-0.488 ; 0.249$ & 0.64 & 0.524 & 0.637 & 0 \\
\hline HF MPFC & 1 & -0.781 & $-1.744 ; 0.182$ & 1.59 & 0.112 & - & - \\
\hline LF MPFC & 2 & -0.108 & $-0.570 ; 0.355$ & 0.46 & 0.648 & 0.976 & 0 \\
\hline LF SFG & 1 & -0.175 & $-0.892 ; 0.542$ & 0.48 & 0.633 & - & - \\
\hline \multicolumn{8}{|l|}{ Method of localization } \\
\hline No neuronavigation & 14 & -0.352 & $\begin{array}{l}-0.531 \\
-0.173\end{array}$ & 3.86 & $<0.001$ & 0.678 & 0 \\
\hline Neuronavigation & 6 & -0.328 & $\begin{array}{l}-0.620 \\
-0.037\end{array}$ & 2.21 & 0.027 & 0.436 & 0 \\
\hline \multicolumn{8}{|l|}{ Number of sessions } \\
\hline Single & 14 & -0.354 & $\begin{array}{l}-0.540 \\
-0.169\end{array}$ & 3.74 & $<0.001$ & 0.934 & 0 \\
\hline Multiple & 6 & -0.321 & $-0.687 ; 0.045$ & 1.72 & 0.086 & 0.121 & 42.6 \\
\hline
\end{tabular}

* Units of analysis: DLPFC, dorsolateral prefrontal cortex; MPFC, medial prefrontal cortex; SFG, superior frontal gyrus; HF, high frequency; LF, low frequency.

\subsection{Safety}

Of all the studies, 33 reported side effect occurrences. rTMS was well-tolerated and the most common side effects were benign discomfort and headache, less frequently insomnia (two studies) and dizziness.

\section{Discussion}

This updated random effects meta-analysis is the first to include all addiction types (SUD and behavioral addiction, including gambling disorder). After excluding outlier studies, our results reveal a small though significant effect size (Hedge's $g=-0.228$ ) favoring real rTMS over shamTMS stimulation in the reduction in craving and for the first time a significant difference between addiction types, with a persistent significant effect only for stimulant and behavioral addictions. In these groups we found a significant correlation between effect size of rTMS intervention and the number of sessions and a trend for the total number of pulses.

The overall effect observed is in line with results from previous meta-analyses $[24,57,68]$ not replicated by other studies $[65,70]$. Direct comparisons are limited by methodological differences, as our study is the only one to include all addiction types, with no restriction on stimulation settings. In particular, Enokibara et al. (2016) and Zhang et al. (2019) restricted their scope to substance use disorder, whereas we show a significant effect in the behavioral addiction group $[65,70]$. Our size effect was consistent with the meta-analysis of Song et al. [57], but it was smaller than in two previous studies $[24,68]$ that found a medium 
effect size (respectively, Hedge's $g=0.476$ and 0.75). These earlier meta-analyses included a smaller number of studies, 9 rTMS studies for Jansen et al., 10 for Maiti et al., and again several methodological differences. Jansen et al. (2013) evaluated effects of both rTMS and transcranial direct current stimulation (tDCS) [24], and Maiti et al. (2016) narrowed their scope to SUD (alcohol and nicotine) and high frequency stimulation [68].

Our meta-analysis is the first to show a significant difference between addiction type, with a persistent significant effect only for stimulant and behavioral addiction. Given the various addiction types included (eight different types), we opted to cluster them into three groups, based for substance use disorder on their classical observed effects: depressant versus stimulant and separating behavioral addiction. These results are consistent with subgroup analyses in previous studies. Thus, our lack of rTMS efficacy on depressants, mainly alcohol use disorder (AUD) (9 units of analysis out of 10), but significant effect on the stimulant group (nicotine, cocaine, and methamphetamine) corroborate the subgroup analyses of Maiti et al. (2016), with no effect on AUD but a persistent effect for nicotine [68]. They are also in line with results from meta-analyses focusing on one addiction type $[67,69]$. Both evaluated rTMS and tDCS effects, respectively, on alcohol craving, with no significant effect found [69], and psychostimulants (cocaine, amphetamine, methamphetamine) with a large size effect only for the rTMS group. Song at al. (2019) and Zhang et al. (2019) found a persistent significant effect in alcohol subgroup analysis but with a smaller effect than for stimulant drugs (nicotine, cocaine, and methamphetamine) [57,70]. Concerning behavioral addiction, our study is the first to include gambling disorder. Although limited to three studies, our results emphasize for the first time the potential of rTMS to reduce craving in this addiction, in which no pharmacological treatment is yet validated. Some previous studies addressed food craving and also found a positive effect of rTMS $[24,57,66]$, but this concept only partially covers eating disorders and limits comparison with our results. Food craving is associated with some forms of overeating behaviors, binge-related eating disorders or obesity [114], but also involves healthy subjects who experience frequent food craving $[115,116]$, who lie outside the scope of this meta-analysis on addictive disorders. We note that our positive results for rTMS on craving in behavioral addictions are strengthened by the methodological quality of the studies included and a low heterogeneity, with no need to exclude outliers. A total of 5 studies out of 6 were assigned low overall risk of bias, versus 7 out of 13 for depressant and 9 out of 16 for stimulant groups.

Differences between addiction types in our meta-analysis could be partly explained by heterogeneity in stimulation settings, such as target and number of sessions. Nevertheless, some authors point out that outside shared psychobiological substrates, there are substantial differences in the neurobiological and behavioral mechanisms underlying different addictions, across drug classes [117] and between substances, particularly AUD and behavioral addictions [118]. Notably, psychostimulants cause more pronounced deficits in impulse control in humans and are associated with complete loss of control in animal models [117]. Most studies still targeted DLPFC, leading most directly to an increased control, which could partly explain rTMS efficacy in this group.

Given the high heterogeneity in stimulation settings, we set out to identify an optimal protocol for the target frequency combination, method of localization, number of sessions, and number of pulses (per session and total). We opted to perform these analyses only in stimulant and behavioral addiction groups but failed to identify optimal combinations of target and stimulation frequency because of insufficient numbers of studies for several variables. Nevertheless, for these groups (stimulant and behavioral addictions), in subgroup analysis, only left DLPFC stimulation showed a persistent favorable effect, mainly with activation variables (10 studies versus 1 for inhibition variables), unlike right DLPFC or other targets, keeping in mind the smaller number of studies in other groups. These findings are in line with the results of Zhang et al. (2019) in SUD [70] and Ma et al. (2019) in psychostimulants [67]. They conflict with those of Enokibara et al. (2016) in SUD, who showed a significant effect only after right DLPFC stimulation [65], and with the conclusions of Jansen et al. in favor of right stimulation despite no statistical difference between left 
and right stimulation in SUD and eating disorders [24]. Discrepancies between included studies could explain this difference in results. In our meta-analysis, DLPFC was mainly chosen, but attention has been paid to novel targets such as the medial prefrontal cortex (MPFC), which could be a more direct pathway to the limbic system [80]. They showed no favorable effect in our results, but the number of studies was small and comprised several variables. A recent controlled study with rTMS targeting medial prefrontal and anterior cingulate cortex in alcohol use disorder showed positive results on craving and alcohol consumption [119].

To go further, craving is a multidimensional phenomenon, which can be modelled on the interplay between three subcomponents-namely, cognitive craving related to cognitive abilities (related to frontal regions); automatic craving, linked to cue response and implicit processes (related to limbic structures); and physiological craving, corresponding to bodily perceptions and related to withdrawal symptoms (related to insular pathways) [120]. According to the target chosen, stimulation could act differently on these different subcomponents and optimally in individualized protocols. Thus, most studies have focused on cognitive craving and control, but targets such as MPFC or insula would respectively act more effectively on automatic or physiological craving.

Our meta-analysis found for stimulant and behavioral groups no additional benefit of neuronavigation to localize targets, contrary to data in depression [121]. However, this result was limited by the fact that most studies still did not use this method in our sample (only 6 used neuronavigation over 20 studies). It would have been interesting to consider the intensity of stimulation in our analysis of stimulation settings, but we were restricted by the limited number of studies included. The comparison between theta burst protocols versus classical ones was also precluded by the fact that only three studies used the first one after sensitivity analysis.

Unlike Song et al. (2019), we found no superiority of multiple versus single sessions, but these studies varied in number (from 4 to 20) and frequency of sessions, with a moderate statistical heterogeneity [57]. In line with the results of Song (2019) and Zhang (2019), we found a correlation between effect size and number of sessions and a trend for the total number of pulses [57,70]. A greater number of sessions and total number of pulses were associated with a greater craving reduction after rTMS intervention. We still lack detailed knowledge on neurobiological mechanisms of rTMS effects in addictive disorders. Nevertheless, translation of findings into animal models or other neurological or psychiatric disorders [122] and results from open-label studies in addiction also suggest that increasing the number of stimulation sessions might help to strengthen the effects of rTMS on the underlying mechanism regulating addictive behaviors, thereby improving its effectiveness [118].

Assessment of clinical rTMS application in addictive disorders with long-lasting effects would optimally require long-term evaluation, combined with usual treatment. When compared or associated with usual treatment, rTMS had an additive positive effect on CBT [95] or nicotine replacement therapy [111] in nicotine use disorder. Only eight studies in our meta-analysis evaluated long-lasting effects after repeated rTMS sessions, with positive results for half of them, at 1 month [106] and 6 months [92] in alcohol use disorder, at 3 months in nicotine [95], and at 3 weeks in methamphetamine use disorder [90]. However, long-lasting neurobiological effects of rTMS on reward and executive networks remain unknown. The cognitive and motivational changes that develop with addiction are associated with long-term changes in brain functions [1] and there is still no evidence that even repeated rTMS sessions could durably modulate these changes. Even so, we can also hypothesize that the "downregulated craving and improved control" therapeutic interval induced by rTMS may offer the possibility of breaking the addiction cycle by enabling patients to gain more benefit from standard drug treatment and rehabilitation programs. Further protocols could also evaluate the efficacy of maintaining rTMS sessions after successful response to initial stimulations, as proposed in depression [123] or in a recent multicenter randomized control trial in tobacco use disorder [124]. Long-term 
positive results of these protocols have also been suggested by an observational study in a large cohort in cocaine use disorder [125].

Our work has some limitations. Studies featured high statistical and methodological heterogeneity, but the consistency of our findings was improved by sensitivity analyses, and secondary analyses were performed to assess which variables could influence results. Nevertheless, the small number of studies included for the evaluation of some variables rule out any definite conclusions. As regards methodological aspects, numerous studies were single-blind, with poor shamTMS quality (e.g., coil angulation) in some studies, and craving outcome in rTMS studies in addictive disorder has been associated with the quality of shamTMS stimulation [115]. Allocation concealment or conditions of self-reported craving assessment were not specified in most studies. Self-report of craving was mainly used for outcome assessment, with various tools (VAS, standardized questionnaires), and is subject to socially desirable responding. Finally, patients' characteristics (e.g., age, sex, motivation) are important to consider when assessing the effects of neuromodulation on craving in SUDs [74] and could not be controlled in the absence of individual data.

To conclude, this meta-analysis was performed on a broader sample of studies than in previous works on this topic, including for the first time all types of addiction, and confirms previous positive results of rTMS effects on craving in addictive disorders, with a small though significant effect favoring treatment. We show a significant difference between addiction groups, with a persistent effect on stimulant (nicotine, cocaine, methamphetamine) and behavioral addiction (eating disorder and gambling disorder). Practical recommendations are still difficult to make because of a high heterogeneity among study protocols and lack of long-term evaluation. Further studies are needed in a larger sample to establish the most effective treatment settings, using repeated sessions, combined or compared with usual treatments, and evaluating the rTMS effect on craving but also on other markers of addiction severity. Long-term effects should be assessed and maintenance protocols for responders considered. Homogenization in methods is needed, but in view of clinical heterogeneity of the addict population, a single neuromodulation protocol may well not fit all subjects. Further work should be conducted with a strategy more closely tailored to subjects' profiles, particularly as regards the target, including also neurophysiological measures.

Supplementary Materials: The following are available online at https:/ / www.mdpi.com/article/10 $.3390 /$ jcm11030624/s1, Figure S1: Detailed risk of bias for each study.

Author Contributions: Conceptualization, A.G., B.P. and G.B.; methodology, B.P.; software, I.D.C. and A.G.; validation, A.G., B.P. and G.B.; formal analysis, B.P. and C.L.; investigation, A.G., J.C., M.D. and V.B.; resources, J.C., I.D.C., P.-M.L., T.C. and A.T.; data curation, B.P.; writing-original draft preparation, A.G.; writing-review and editing, B.P., G.B. and J.C.; visualization, A.G. and J.C.; supervision, G.B.; project administration, G.B. All authors have read and agreed to the published version of the manuscript.

Funding: This research received no external funding.

Institutional Review Board Statement: Not applicable.

Informed Consent Statement: Not applicable.

Acknowledgments: The authors thank Nathalie PIÑOL from the health department of the Clermont Auvergne University Library and the staff of the University Health Library of Paris University for their assistance in the bibliographic survey.

Conflicts of Interest: The authors declare no conflict of interest. 


\section{Appendix A}

Table A1. Characteristics of studies included in the meta-analysis $(k=34)$.

\begin{tabular}{|c|c|c|c|c|c|c|c|c|}
\hline \multirow[b]{2}{*}{ Studies } & \multirow[b]{2}{*}{ Design } & \multirow[b]{2}{*}{ Population } & \multicolumn{4}{|c|}{ Stimulation Settings } & \multirow{2}{*}{$\begin{array}{l}\text { Method of Craving } \\
\text { Assessment and Other } \\
\text { Outcome Measures }{ }^{2} \\
{ }^{*} \text { Craving as Primary } \\
\text { Outcome }\end{array}$} & \multirow[b]{2}{*}{ Main Results } \\
\hline & & & $\begin{array}{l}\text { No. of Sessions }{ }^{1} \\
\text { Total } \\
\text { Pulses/Session } \\
\end{array}$ & $\begin{array}{l}\text { Frequency }(\mathrm{Hz}) \\
\text { Intensity }(\% \text { of } \\
\text { RMT) }\end{array}$ & $\begin{array}{l}\text { Stimulation Site } \\
\text { Method for } \\
\text { Locating Target } \\
\end{array}$ & $\begin{array}{l}\text { Coil } \\
\text { Type of shamTMS }\end{array}$ & & \\
\hline \multicolumn{9}{|l|}{ Alcohol } \\
\hline $\begin{array}{l}\text { Mishra et al., } \\
2010 \text { [106] }\end{array}$ & $\mathrm{RCT}, \mathrm{SB}$ & $\begin{array}{l}45 \mathrm{M}, 30 \mathrm{real} / 15 \\
\text { shamTMS, detoxified }\end{array}$ & $\begin{array}{l}10 \\
1000\end{array}$ & $\begin{array}{l}10 \mathrm{~Hz} \\
110 \%\end{array}$ & $\begin{array}{l}\text { R DLPFC } \\
\text { NS }\end{array}$ & $\begin{array}{l}\text { Figure-of- } 8 \\
\text { ShamTMS coil }\end{array}$ & $\begin{array}{l}\text { ACQ-NOW *, before, after, } \\
\text { and } 1 \text { month after last } \\
\text { session }\end{array}$ & $\begin{array}{l}\text { Significant post-rTMS } \\
\text { reduction }\end{array}$ \\
\hline $\begin{array}{l}\text { Höppner et al., } \\
2011 \text { [81] }\end{array}$ & RCT, SB & $\begin{array}{l}19 \mathrm{~F}, 10 \mathrm{real} / 9 \\
\text { shamTMS, detoxified }\end{array}$ & $\begin{array}{l}10 \\
1000\end{array}$ & $\begin{array}{l}20 \mathrm{~Hz} \\
90 \%\end{array}$ & $\begin{array}{l}\text { L DLPFC } \\
10-20 \text { syst }\end{array}$ & $\begin{array}{l}\text { Figure-of- } 8 \\
45^{\circ} \text { angulation and } \\
\text { shifting }\end{array}$ & $\begin{array}{l}\text { OCDS * } \\
\text { Mood (HDRS, BDI) } \\
\text { Attentional blink }\end{array}$ & $\begin{array}{l}\text { No significant effect on } \\
\text { craving and mood }\end{array}$ \\
\hline $\begin{array}{l}\text { Herremans et al., } \\
2012 \text { [99] }\end{array}$ & $\mathrm{RCT}, \mathrm{SB}$ & $\begin{array}{l}31 \text { inpatients } \\
\text { ( } 36 \text { included), } \\
15 \text { real } / 16 \text { shamTMS, } \\
21 \mathrm{M} / 10 \mathrm{~F} \text {, } \\
\text { detoxified }\end{array}$ & $\begin{array}{l}1 \\
1560\end{array}$ & $\begin{array}{l}20 \mathrm{~Hz} \\
110 \%\end{array}$ & $\begin{array}{l}\text { R DLPFC } \\
\text { Neuronavigation }\end{array}$ & $\begin{array}{l}\text { Figure-of- } 8 \\
90^{\circ} \text { angulation }\end{array}$ & $\begin{array}{l}\text { OCDS* } \\
\text { Before, after, and the } \\
3 \text { days following rTMS in } \\
\text { natural setting }\end{array}$ & $\begin{array}{l}\text { No significant effect on } \\
\text { craving (immediate or } \\
\text { delayed) }\end{array}$ \\
\hline $\begin{array}{l}\text { Herremans et al., } \\
2013 \text { [100] }\end{array}$ & $\begin{array}{l}\mathrm{RCT}, \mathrm{SB} \text {, crossover, } \\
1 \text { week washout }\end{array}$ & $\begin{array}{l}29 \text { inpatients } \\
\text { (50 included), } \\
19 \mathrm{M} / 10 \mathrm{~F}, \\
\text { detoxified }\end{array}$ & $\begin{array}{l}1 \\
1560\end{array}$ & $\begin{array}{l}20 \mathrm{~Hz} \\
110 \%\end{array}$ & $\begin{array}{l}\text { R DLPFC } \\
\text { Neuronavigation }\end{array}$ & $\begin{array}{l}\text { Figure-of- } 8 \\
90^{\circ} \text { angulation }\end{array}$ & $\begin{array}{l}\text { OCDS } \\
\text { Go/NoGo test }\end{array}$ & $\begin{array}{l}\text { No significant effect on } \\
\text { craving } \\
\text { Effect on IIRTV on } \\
\text { Go/NoGo }\end{array}$ \\
\hline $\begin{array}{l}\text { Herremans et al., } \\
2015 \text { [101] }\end{array}$ & $\begin{array}{l}\text { Phase 1: RCT, DB, } \\
1 \text { session } \\
\text { Phase 2: NC }\end{array}$ & $\begin{array}{l}26 \text { (Phase 2: 23), } \\
13 \text { real/13 shamTMS, } \\
17 \mathrm{M} / 9 \mathrm{~F} \text {, detoxified }\end{array}$ & $\begin{array}{l}\text { Phase 1: } 1 \\
\text { Phase 2: } 15 \text {, for } \\
4 \text { days } \\
1560\end{array}$ & $\begin{array}{l}20 \mathrm{~Hz} \\
110 \%\end{array}$ & $\begin{array}{l}\text { R DLPFC } \\
\text { Neuronavigation }\end{array}$ & $\begin{array}{l}\text { Figure-of- } 8 \\
90^{\circ} \text { angulation }\end{array}$ & $\begin{array}{l}\text { Craving cue-induced: TLS } \\
* \text {, before rTMS, day1 and } 7 \\
\text { General craving: AUQ } \\
\text { and OCDS, before rTMS, } \\
\text { day } 7 \\
\text { fMRI, before rTMS, day1 } \\
\text { and } 7\end{array}$ & $\begin{array}{l}\text { No significant effect on } \\
\text { cue-induced craving } \\
\text { Significant reduction in } \\
\text { general craving after } \\
\text { phase } 2\end{array}$ \\
\hline $\begin{array}{l}\text { Ceccanti et al., } \\
2015 \text { [92] } \\
\text { dTMS }\end{array}$ & RCT, DB & $\begin{array}{l}18 \mathrm{M}, 9 \mathrm{real} / 9 \\
\text { shamTMS, detoxified } \\
\text { for } 10 \text { days }\end{array}$ & $\begin{array}{l}10 \\
1500\end{array}$ & $\begin{array}{l}20 \mathrm{~Hz} \\
120 \%\end{array}$ & $\begin{array}{l}\text { MPFC } \\
5 \mathrm{~cm}\end{array}$ & $\begin{array}{l}\text { H coil } \\
\text { ShamTMS coil }\end{array}$ & $\begin{array}{l}\text { VAS (cue-induced) } \\
\text { Alcohol consumption, } \\
\text { cortisolemia, and } \\
\text { prolactinemia } \\
\text { Before, after rTMS and } \\
\text { each month to } 6 \text { months }\end{array}$ & $\begin{array}{l}\text { Significant reduction in } \\
\text { craving (maintained at } \\
1 \text { month), alcohol } \\
\text { consumption, } \\
\text { cortisolemia, and } \\
\text { prolactinemia }\end{array}$ \\
\hline
\end{tabular}


Table A1. Cont.

\begin{tabular}{|c|c|c|c|c|c|c|c|c|}
\hline \multirow[b]{2}{*}{ Studies } & \multirow[b]{2}{*}{ Design } & \multirow[b]{2}{*}{ Population } & \multicolumn{4}{|c|}{ Stimulation Settings } & \multirow{2}{*}{$\begin{array}{l}\text { Method of Craving } \\
\text { Assessment and Other } \\
\text { Outcome Measures }{ }^{2} \\
{ }^{*} \text { Craving as Primary } \\
\text { Outcome }\end{array}$} & \multirow[b]{2}{*}{ Main Results } \\
\hline & & & $\begin{array}{l}\text { No. of Sessions }{ }^{1} \\
\text { Total } \\
\text { Pulses/Session } \\
\end{array}$ & $\begin{array}{l}\text { Frequency }(\mathrm{Hz}) \\
\text { Intensity (\% of } \\
\text { RMT) }\end{array}$ & $\begin{array}{l}\text { Stimulation Site } \\
\text { Method for } \\
\text { Locating Target }\end{array}$ & $\begin{array}{l}\text { Coil } \\
\text { Type of shamTMS }\end{array}$ & & \\
\hline $\begin{array}{l}\text { Del Felice } \\
\text { et al., } 2016 \text { [94] }\end{array}$ & RCT, SB & $\begin{array}{l}17 \text { inpatients }(20 \\
\text { included), } \\
8 \text { real } / 9 \text { shamTMS, } \\
13 \mathrm{M} / 4 \mathrm{~F} \\
\text { During } \\
\text { detoxification }\end{array}$ & $\begin{array}{l}4 \text { (2/week, } \\
2 \text { weeks) } \\
1000\end{array}$ & $\begin{array}{l}10 \mathrm{~Hz} \\
100 \%\end{array}$ & $\begin{array}{l}\text { L DLPFC } \\
10-20 \text { syst }\end{array}$ & $\begin{array}{l}\text { Figure-of-8 } \\
\text { ShamTMS: wooden } \\
\text { panel under coil }\end{array}$ & $\begin{array}{l}\text { VAS } \\
\text { Alcohol intake, EEG, Stroop, } \\
\text { and Go/NoGo tasks } \\
\text { Before and after rTMS } \\
\text { sessions, at } 1 \text { month }\end{array}$ & $\begin{array}{l}\text { No effect on craving } \\
\text { and alcohol intake } \\
\text { Significant reduction in } \\
\text { fast EEG frequencies } \\
\text { Effect on Stroop and } \\
\text { Go/NoGo }\end{array}$ \\
\hline $\begin{array}{l}\text { Hanlon et al., } \\
2017^{* *}[98]\end{array}$ & $\begin{array}{l}\text { RCT, SB, crossover, } \\
7-14 \text { days washout }\end{array}$ & $\begin{array}{l}24 \text { non-treatment- } \\
\text { seeking } \\
\text { alcohol-dependent, } \\
17 \mathrm{M} / 7 \mathrm{~F}\end{array}$ & $\begin{array}{l}1 \\
3600\end{array}$ & $\begin{array}{l}\text { cTBS } \\
110 \%\end{array}$ & $\begin{array}{l}\text { L FP } \\
10-20 \text { syst }\end{array}$ & $\begin{array}{l}\text { Figure-of-8 } \\
\text { ShamTMS coil }\end{array}$ & $\begin{array}{l}\text { VAS (cue-induced) } \\
\text { fMRI before and after cTBS } \\
\text { (change in MPFC-striatal } \\
\text { connectivity) }\end{array}$ & $\begin{array}{l}\text { No effect on craving } \\
\text { Decreased evoked } \\
\text { BOLD signal in left } \\
\text { OFC, insula, and lateral } \\
\text { sensorimotor cortex }\end{array}$ \\
\hline $\begin{array}{l}\text { Jansen et al., } \\
2019 \text { [82] }\end{array}$ & $\mathrm{CT}, \mathrm{SB}$ & $\begin{array}{l}39,19 \mathrm{real} / 20 \\
\text { shamTMS, } \\
26 \mathrm{M} / 13 \mathrm{~F} \text {, Subjects } \\
\text { sober for at least } \\
3 \text { weeks } \\
36 \mathrm{HC}\end{array}$ & $\begin{array}{l}1 \\
3000\end{array}$ & $\begin{array}{l}10 \mathrm{~Hz} \\
110 \%\end{array}$ & $\begin{array}{l}\text { R DLPFC } \\
\text { Neuronavigation } \\
\text { guided by fMRI }\end{array}$ & $\begin{array}{l}\text { Figure-of- } 8 \\
90^{\circ} \text { angulation }\end{array}$ & $\begin{array}{l}\text { AUQ before and after the } \\
\text { emotional reappraisal task, } \\
\text { after rTMS } \\
\text { Emotion regulation and } \\
\text { related brain activity using } \\
\text { fMRI }\end{array}$ & $\begin{array}{l}\text { No effect on craving } \\
\text { In AUD patients: } \\
\text { reduced self-reported } \\
\text { emotions to positive } \\
\text { and negative images, } \\
\text { reduced right DLPFC } \\
\text { activity but no } \\
\text { significant effect of } \\
\text { rTMS on } \\
\text { reappraisal-related } \\
\text { brain function }\end{array}$ \\
\hline $\begin{array}{l}\text { Perini et al., } \\
2019 \text { [86] } \\
\text { dTMS }\end{array}$ & RCT, DB & $\begin{array}{l}56 \text { ( } 45 \text { finished } \\
\text { sessions), } \\
29 \text { real/27 shamTMS } \\
\text { (23/22 finished), } \\
\text { treatment-seeking } \\
\text { alcohol-dependent } \\
\text { patients }\end{array}$ & $\begin{array}{l}15 \text { (5/week, } \\
3 \text { weeks) } \\
1500\end{array}$ & $\begin{array}{l}10 \mathrm{~Hz} \\
120 \%\end{array}$ & $\begin{array}{l}\text { Insula bilat and } \\
\text { overlaying areas } \\
\text { excluding ant PFC }\end{array}$ & $\begin{array}{l}\text { H coil, H8 } \\
\text { ShamTMS coil }\end{array}$ & $\begin{array}{l}\text { AUQ cue-induced before } \\
\text { each session; PACS during } \\
\text { rTMS and follow-up (week } \\
\text { 1,2, } 4,8,12 \text { ) } \\
\text { Consumption during rTMS, } \\
\text { at the end of sessions and } \\
\text { during follow-up; CGI and } \\
\text { CRPS-SA during rTMS } \\
\text { follow-up } \\
\text { Structural and rsMRI before } \\
\text { and after rTMS sessions }\end{array}$ & $\begin{array}{l}\text { Decrease in craving and } \\
\text { drinking measures but } \\
\text { with no difference } \\
\text { between real and } \\
\text { shamTMS rTMS } \\
\text { Difference in rs insula } \\
\text { connectivity after } \\
\text { treatment between real } \\
\text { and shamTMS groups }\end{array}$ \\
\hline
\end{tabular}


Table A1. Cont.

\begin{tabular}{|c|c|c|c|c|c|c|c|c|}
\hline \multirow[b]{2}{*}{ Studies } & \multirow[b]{2}{*}{ Design } & \multirow[b]{2}{*}{ Population } & \multicolumn{4}{|l|}{ Stimulation Settings } & \multirow{2}{*}{$\begin{array}{l}\text { Method of Craving } \\
\text { Assessment and Other } \\
\text { Outcome Measures }{ }^{2} \\
{ }^{*} \text { Craving as Primary } \\
\text { Outcome }\end{array}$} & \multirow[b]{2}{*}{ Main Results } \\
\hline & & & $\begin{array}{l}\text { No. of Sessions }{ }^{1} \\
\text { Total } \\
\text { Pulses/Session } \\
\end{array}$ & $\begin{array}{l}\text { Frequency }(\mathrm{Hz}) \\
\text { Intensity }(\% \text { of } \\
\text { RMT) }\end{array}$ & $\begin{array}{l}\text { Stimulation Site } \\
\text { Method for } \\
\text { Locating Target } \\
\end{array}$ & $\begin{array}{l}\text { Coil } \\
\text { Type of shamTMS }\end{array}$ & & \\
\hline \multicolumn{9}{|l|}{ Cannabis } \\
\hline $\begin{array}{l}\text { Sahlem et al., } \\
2018 \text { [107] }\end{array}$ & $\begin{array}{l}\mathrm{RCT}, \mathrm{DB}, \\
\text { crossover, } 1 \text { week } \\
\text { washout }\end{array}$ & $\begin{array}{l}16 \text { ( } 2 \text { subjects } \\
\text { withdrew before first } \\
\text { session), } 13 \mathrm{M} / 3 \mathrm{~F}\end{array}$ & $\begin{array}{l}1 \\
4000\end{array}$ & $\begin{array}{l}10 \mathrm{~Hz} \\
110 \%\end{array}$ & $\begin{array}{l}\text { L DLPFC } \\
\text { Beam F3 method }\end{array}$ & $\begin{array}{l}\text { Figure-of- } 8 \\
\text { ShamTMS coil }\end{array}$ & $\begin{array}{l}\text { MCQ (cue-induced) prior, } \\
\text { during, after, and } 15 \text { min } \\
\text { after the completion of } \\
\text { rTMS }\end{array}$ & $\begin{array}{l}\text { No effect on craving } \\
\text { Feasibility and safety } \\
\text { validated }\end{array}$ \\
\hline $\begin{array}{l}\text { Opiate } \\
\text { Shen et al., } \\
2016 \text { [108] }\end{array}$ & $\mathrm{RCT}$ & $\begin{array}{l}20 \mathrm{M}, \\
10 \mathrm{real} / 10 \text { shamTMS, } \\
\text { long-term addicts }\end{array}$ & $\begin{array}{l}5 \\
2000\end{array}$ & $\begin{array}{l}10 \mathrm{~Hz} \\
100 \%\end{array}$ & $\begin{array}{l}\text { L DLPFC } \\
\text { NS, no MRI }\end{array}$ & $\begin{array}{l}\text { Figure-of- } 8 \\
90^{\circ} \text { angulation }\end{array}$ & $\begin{array}{l}\text { VAS* (cue-induced) } \\
\text { Before, after 1st and last } \\
\text { session }\end{array}$ & $\begin{array}{l}\text { Significant effect on } \\
\text { craving at day } 1 \text { and } 5\end{array}$ \\
\hline \multicolumn{9}{|l|}{$\begin{array}{l}\text { Stimulant } \\
\text { group } \\
\text { Nicotine }\end{array}$} \\
\hline $\begin{array}{l}\text { Johann et al., } \\
2003 \text { [102] }\end{array}$ & $\begin{array}{l}\mathrm{RCT}, \mathrm{DB}, \\
\text { crossover, } \\
2 \text { consecutive days }\end{array}$ & $\begin{array}{l}11,2 \mathrm{M} / 9 \mathrm{~F} \\
\text { motivated to quit }\end{array}$ & $\begin{array}{l}1 \\
1000\end{array}$ & $\begin{array}{l}20 \mathrm{~Hz} \\
90 \%\end{array}$ & $\begin{array}{l}\text { L DLPFC } \\
\text { NS }\end{array}$ & $\begin{array}{l}\text { Figure-of- } 8 \\
45-90^{\circ} \text { angulation }\end{array}$ & VAS * & $\begin{array}{l}\text { Significant craving } \\
\text { reduction }\end{array}$ \\
\hline $\begin{array}{l}\text { Amiaz et al., } \\
2009 \text { [93] }\end{array}$ & $\begin{array}{l}\text { RCT, DB, } 4 \text { arms: } \\
\text { real/shamTMS, } \\
\text { smoke/neutral cue }\end{array}$ & $\begin{array}{l}48,26 \text { real } / 22 \\
\text { shamTMS (smoke } \\
\text { cue: } 12 / 9 \text { ), } \\
21 \mathrm{M} / 27 \mathrm{~F} \\
\geq 20 \mathrm{cig} / \text { day }\end{array}$ & $\begin{array}{l}10 \text { and } \\
\text { maintenance } \\
\text { phase: } 6 \text { over } \\
1 \text { month } \\
1000\end{array}$ & $\begin{array}{l}10 \mathrm{~Hz} \\
100 \%\end{array}$ & $\begin{array}{l}\text { L DLPFC } \\
5 \mathrm{~cm}\end{array}$ & $\begin{array}{l}\text { Figure-of-8 } \\
\text { ShamTMS coil }\end{array}$ & $\begin{array}{l}\text { Cue-induced craving * by } \\
\text { VAS and sTCQ, } \\
\text { Consumption and } \\
\text { nicotine dependence } \\
\text { (FTND) } \\
\text { Before, after rTMS and at } \\
6 \text { months }\end{array}$ & $\begin{array}{l}\text { Significant effect on } \\
\text { cue-induced-smoke } \\
\text { craving, on } \\
\text { consumption and } \\
\text { dependence } \\
\text { No difference at } \\
6 \text { months }\end{array}$ \\
\hline $\begin{array}{l}\text { Rose et al., } \\
2011 \text { [88] }\end{array}$ & $\begin{array}{l}\text { RCT, crossover, } \\
3 \text { visits }(1 \mathrm{~Hz}, \\
10 \mathrm{~Hz} \text {, and } \\
\text { shamTMS })\end{array}$ & $\begin{array}{l}15,8 \mathrm{M} / 7 \mathrm{~F}, \\
\geq 20 \mathrm{cig} / \text { day, with } \\
\text { good cue reactivity }\end{array}$ & $\begin{array}{l}1 \text { at each frequency } \\
1 \mathrm{~Hz}: 450 / 10 \mathrm{~Hz}: \\
4500\end{array}$ & $\begin{array}{l}1 \text { and } 10 \mathrm{~Hz} \\
90 \%\end{array}$ & $\begin{array}{l}\text { SFG } \\
10-20 \text { syst }\end{array}$ & $\begin{array}{l}\text { Figure-of-8 } \\
\text { ShamTMS: motor } \\
\text { cortex stimulation }\end{array}$ & $\begin{array}{l}\text { Shiffman-Jarvik } \\
\text { questionnaire } \\
\text { (cue-induced, } \\
\text { neutral/smoke) } \\
\text { Cigarette evaluation } \\
\text { questionnaire }\end{array}$ & $\begin{array}{l}\text { Cue-induced craving } \\
\text { increase at } 10 \mathrm{~Hz} \text { but } \\
\text { decrease if neutral cue }\end{array}$ \\
\hline $\begin{array}{l}\text { Li et al., } \\
2013 \text { [103] }\end{array}$ & $\begin{array}{l}\mathrm{RCT}, \mathrm{DB}, \\
\text { crossover, } \\
1 \text { week washout }\end{array}$ & $\begin{array}{l}14(16 \text { included }) \\
10 \mathrm{M} / 4 \mathrm{~F} \text {, non- } \\
\text { treatment-seeking }\end{array}$ & $\begin{array}{l}1 \\
3000\end{array}$ & $\begin{array}{l}10 \mathrm{~Hz} \\
100 \%\end{array}$ & $\begin{array}{l}\text { L DLPFC } \\
6 \mathrm{~cm}\end{array}$ & $\begin{array}{l}\text { Figure-of-8 } \\
\text { ShamTMS coil }\end{array}$ & $\begin{array}{l}\text { QSU-B (cue-induced, } \\
\text { neutral/smoke) * }\end{array}$ & $\begin{array}{l}\text { Significant effect on } \\
\text { craving, correlated with } \\
\text { dependence severity }\end{array}$ \\
\hline $\begin{array}{l}\text { Pripfl et al., } \\
2014 \text { [87] }\end{array}$ & $\begin{array}{l}\mathrm{RCT} \text {, cross over, } \\
1 \text { week washout }\end{array}$ & $\begin{array}{l}11 \text { (14 included), } \\
5 \mathrm{M} / 6 \mathrm{~F} \text {, abstinent } \\
\text { for } 6 \mathrm{~h}\end{array}$ & $\begin{array}{l}1 \\
1200\end{array}$ & $\begin{array}{l}10 \mathrm{~Hz} \\
90 \%\end{array}$ & $\begin{array}{l}\text { L DLPFC } \\
\text { Neuronavigation }\end{array}$ & $\begin{array}{l}\text { Figure-of-8 } \\
\text { ShamTMS: vertex } \\
\text { stimulation }\end{array}$ & $\begin{array}{l}5 \text { points LS } \\
\text { (cue-induced)* } \\
\text { EEG }\end{array}$ & $\begin{array}{l}\text { Significant reduction in } \\
\text { craving and EEG delta } \\
\text { power }\end{array}$ \\
\hline
\end{tabular}


Table A1. Cont.

\begin{tabular}{|c|c|c|c|c|c|c|c|c|}
\hline \multirow[b]{2}{*}{ Studies } & \multirow[b]{2}{*}{ Design } & \multirow[b]{2}{*}{ Population } & \multicolumn{4}{|c|}{ Stimulation Settings } & \multirow{2}{*}{$\begin{array}{l}\text { Method of Craving } \\
\text { Assessment and Other } \\
\text { Outcome Measures }{ }^{2} \\
{ }^{*} \text { Craving as Primary } \\
\text { Outcome }\end{array}$} & \multirow[b]{2}{*}{ Main Results } \\
\hline & & & $\begin{array}{l}\text { No. of Sessions }{ }^{1} \\
\text { Total } \\
\text { Pulses/Session } \\
\end{array}$ & $\begin{array}{l}\text { Frequency }(\mathrm{Hz}) \\
\text { Intensity }(\% \text { of } \\
\text { RMT) }\end{array}$ & $\begin{array}{l}\text { Stimulation Site } \\
\text { Method for } \\
\text { Locating Target } \\
\end{array}$ & $\begin{array}{l}\text { Coil } \\
\text { Type of shamTMS }\end{array}$ & & \\
\hline \multirow{2}{*}{$\begin{array}{l}\text { Diehler et al., } \\
2014 \text { [95] }\end{array}$} & RCT, DB & 74 & 4 (2/week) & iTBS & R DLPFC & Figure-of- 8 & QSU * before CBT and & No effect on craving \\
\hline & $\begin{array}{l}\text { Add-on a } \\
\text { 6-sessions group } \\
\text { CBT, rTMS at } \\
\text { meetings } 3 \text { to } 6\end{array}$ & $\begin{array}{l}38 \mathrm{real} / 36 \text { shamTMS, } \\
40 \mathrm{M} / 34 \mathrm{~F}\end{array}$ & 600 & $80 \%$ & 10-20 syst & $\begin{array}{l}\text { ShamTMS: } 45^{\circ} \\
\text { angulation and } 60 \% \\
\text { RMT }\end{array}$ & $\begin{array}{l}\text { after last rTMS session } \\
\text { Abstinence rate at } 3,6 \text {, } \\
\text { and } 12 \text { months }\end{array}$ & $\begin{array}{l}\text { Significant effect on } \\
\text { abstinence rate at } \\
3 \text { months }\end{array}$ \\
\hline $\begin{array}{l}\text { Trojak et al., } \\
2015 \text { [111] }\end{array}$ & $\mathrm{RCT}, \mathrm{DB}$ & 37 & 10 & $1 \mathrm{~Hz}$ & R DLPFC & Figure-of- 8 & VAS, FTCQ-12, and QSU & No significant effect of \\
\hline \multirow{2}{*}{$\begin{array}{l}\text { Li et al., } \\
2017 \text { [104] }\end{array}$} & $\mathrm{RCT}, \mathrm{SB}$, crossover, & $11,5 \mathrm{M} / 6 \mathrm{~F}$ & 1 & $10 \mathrm{~Hz}$ & L DLPFC & Figure-of-8 & VAS (cue-induced) & No effect on craving \\
\hline & 1 week washout & & 3000 & $100 \%$ & $6 \mathrm{~cm}$ & ShamTMS coil & Resting state fMRI & $\begin{array}{l}\text { Decreased fALFF in the } \\
\text { right insula and } \\
\text { thalamus and temporal } \\
\text { connectivity between L } \\
\text { DLPFC and L OMPFC }\end{array}$ \\
\hline \multicolumn{9}{|r|}{ 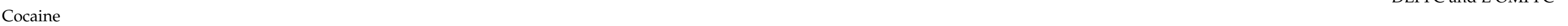 } \\
\hline Hanlon et al., & $\mathrm{RCT}, \mathrm{SB}$, crossover, & $11,9 \mathrm{M} / 2 \mathrm{~F}$, non- & 1 & cTBS & L MPFC & Figure-of-8 & VAS * & Significant decrease in \\
\hline 2015 [80] & 7-14 days washout & treatment-seeking & 3600 & $110 \%$ & $10-20$ syst & ShamTMS coil & fMRI & $\begin{array}{l}\text { craving and striatum } \\
\text { and ant insula activity }\end{array}$ \\
\hline \multirow{2}{*}{$\begin{array}{l}\text { Hanlon et al., } \\
2017^{* *}[98]\end{array}$} & $\mathrm{RCT}, \mathrm{SB}$, crossover, & 25, 12 M/13 F, non- & 1 & cTBS & L FP & Figure-of-8 & VAS (cue-induced) & No effect on craving \\
\hline & 7-14 days washout & $\begin{array}{l}\text { treatment-seeking } \\
\text { chronic cocaine users } \\
\text { abstinent for } 48 \mathrm{~h}\end{array}$ & 3600 & $110 \%$ & 10-20 syst & ShamTMS coil & $\begin{array}{l}\text { fMRI before and after } \\
\text { cTBS (change in } \\
\text { MPFC-striatal } \\
\text { connectivity) }\end{array}$ & $\begin{array}{l}\text { Decreased evoked } \\
\text { BOLD signal in the } \\
\text { caudate, accumbens, } \\
\text { anterior cingulate, } \\
\text { orbitofrontal and } \\
\text { parietal cortex }\end{array}$ \\
\hline \multicolumn{9}{|c|}{ Methamphetamine } \\
\hline $\begin{array}{l}\text { Li et al., } \\
2013 \text { [89] }\end{array}$ & $\begin{array}{l}\mathrm{RCT}, \mathrm{SB} \text {, crossover, } \\
1 \mathrm{~h} \text { washout }\end{array}$ & $\begin{array}{l}18,10 \mathrm{MA} \\
\text { dependent and } \\
8 \text { healthy controls, } \\
4 \mathrm{M} / 14 \mathrm{~F}\end{array}$ & $\begin{array}{l}1 \\
900\end{array}$ & $\begin{array}{l}1 \mathrm{~Hz} \\
100 \%\end{array}$ & $\begin{array}{l}\text { L DLPFC } \\
6 \mathrm{~cm}\end{array}$ & $\begin{array}{l}\text { Figure-of- } 8 \\
45^{\circ} \text { angulation }\end{array}$ & $\begin{array}{l}\text { VAS (cue-induced, } \\
\text { neutral/MA) * during } \\
\text { rTMS session }\end{array}$ & $\begin{array}{l}\text { For MA dependent only: } \\
\text { significant craving } \\
\text { increase }\end{array}$ \\
\hline
\end{tabular}


Table A1. Cont.

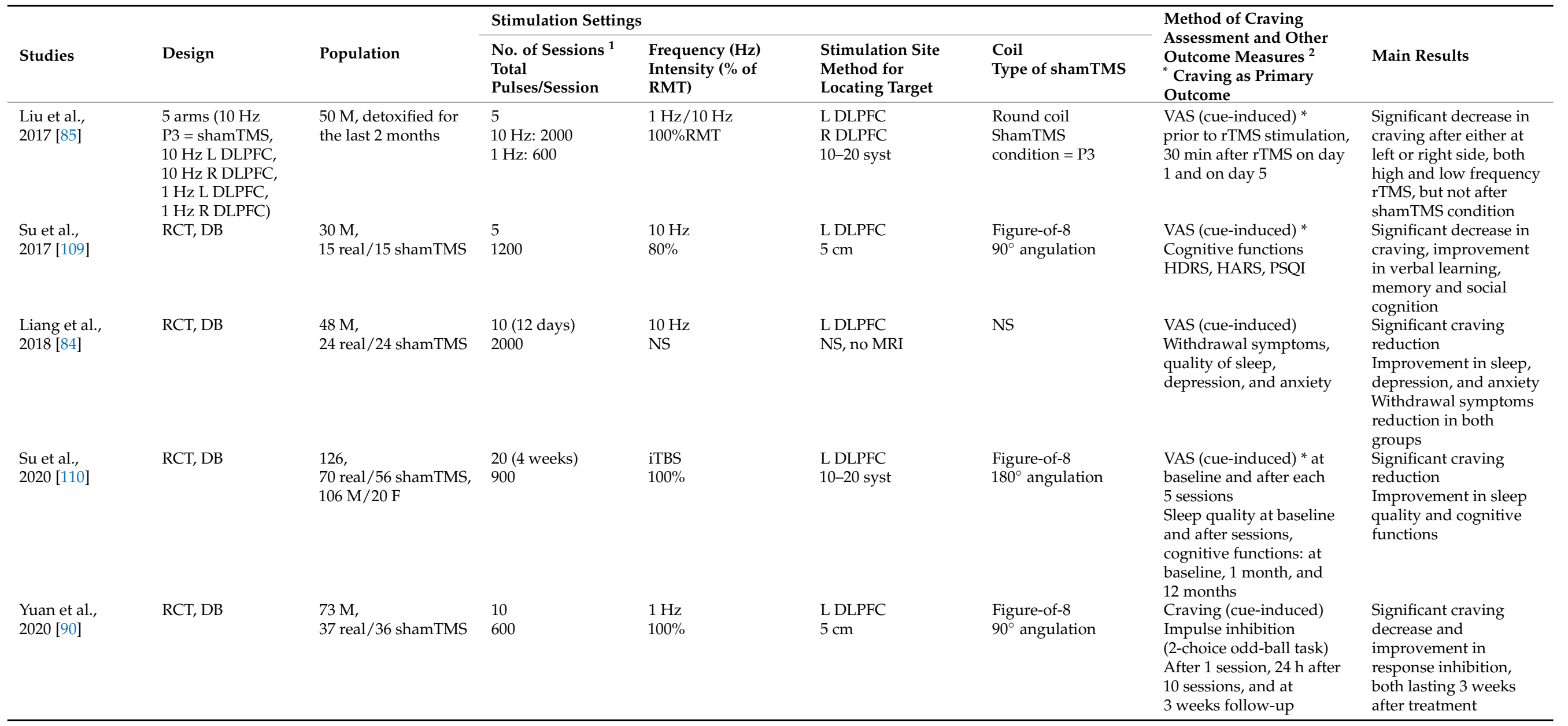


Table A1. Cont.

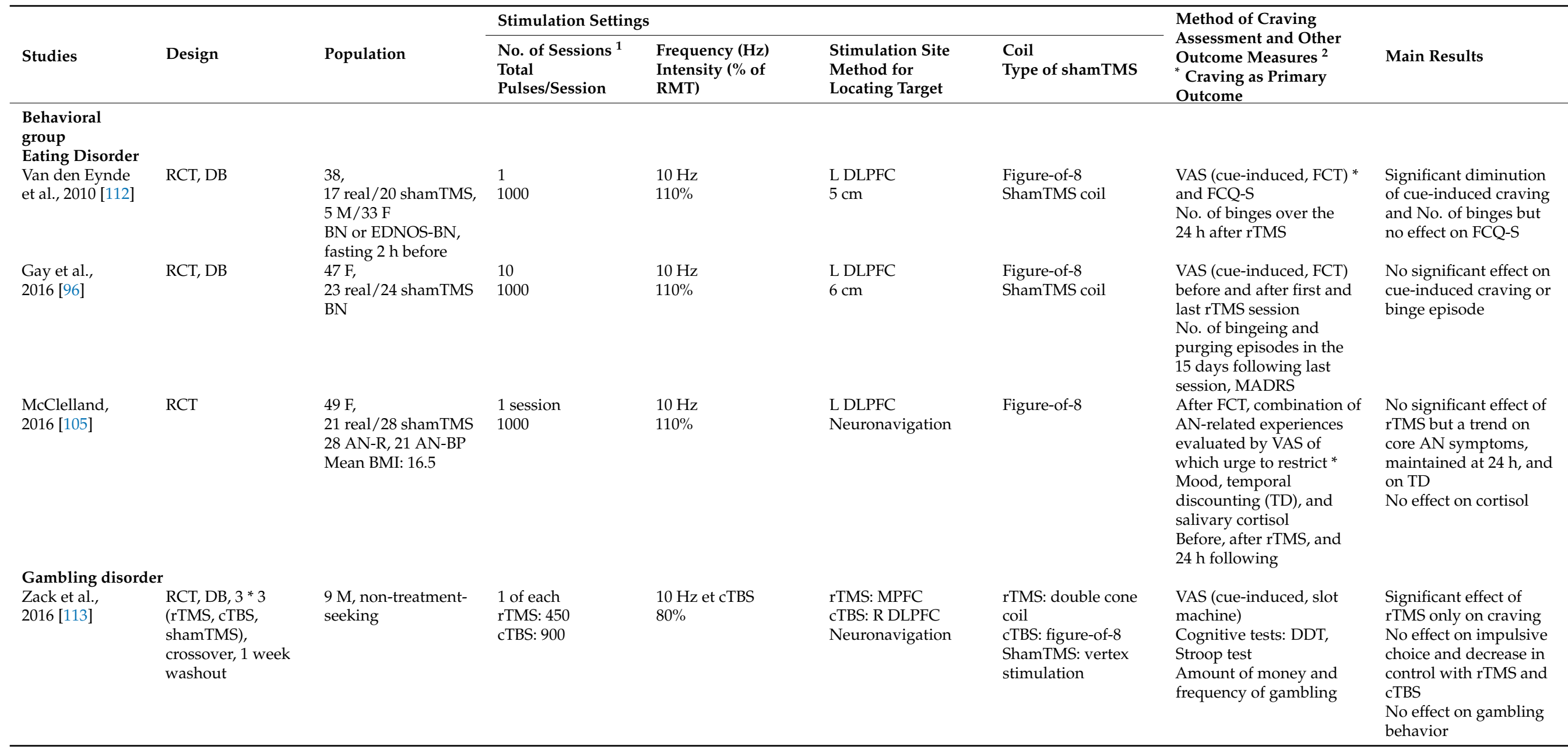


Table A1. Cont.

\begin{tabular}{|c|c|c|c|c|c|c|c|c|}
\hline \multirow[b]{2}{*}{ Studies } & \multirow[b]{2}{*}{ Design } & \multirow[b]{2}{*}{ Population } & \multicolumn{4}{|c|}{ Stimulation Settings } & \multirow{2}{*}{$\begin{array}{l}\text { Method of Craving } \\
\text { Assessment and Other } \\
\text { Outcome Measures }{ }^{2} \\
{ }^{*} \text { Craving as Primary } \\
\text { Outcome }\end{array}$} & \multirow[b]{2}{*}{ Main Results } \\
\hline & & & $\begin{array}{l}\text { No. of Sessions }{ }^{1} \\
\text { Total } \\
\text { Pulses/Session }\end{array}$ & $\begin{array}{l}\text { Frequency }(\mathrm{Hz}) \\
\text { Intensity }(\% \text { of } \\
\text { RMT) }\end{array}$ & $\begin{array}{l}\text { Stimulation Site } \\
\text { Method for } \\
\text { Locating Target }\end{array}$ & $\begin{array}{l}\text { Coil } \\
\text { Type of shamTMS }\end{array}$ & & \\
\hline $\begin{array}{l}\text { Gay et al., } \\
2017 \text { [97] }\end{array}$ & $\begin{array}{l}\text { RCT, DB, } \\
\text { crossover, } 1 \text { week } \\
\text { washout }\end{array}$ & $\begin{array}{l}22,14 \mathrm{M} / 8 \mathrm{~F} \\
\text { treatment-seeking }\end{array}$ & $\begin{array}{l}1 \\
3008\end{array}$ & $\begin{array}{l}10 \mathrm{~Hz} \\
110 \%\end{array}$ & $\begin{array}{l}\text { L DLPFC } \\
\text { Neuronavigation }\end{array}$ & $\begin{array}{l}\text { Figure-of-8 } \\
\text { ShamTMS coil }\end{array}$ & $\begin{array}{l}\text { VAS (cue-induced) } \\
\text { Gambling behavior before } \\
\text { and } 7 \text { days after rTMS }\end{array}$ & $\begin{array}{l}\text { Significant effect on } \\
\text { craving, no effect on } \\
\text { gambling behavior }\end{array}$ \\
\hline $\begin{array}{l}\text { Sauvaget et al., } \\
2018 \text { [89] }\end{array}$ & $\begin{array}{l}\text { RCT, DB, } \\
\text { crossover, } \\
1-2 \text { weeks } \\
\text { washout }\end{array}$ & 30 & $\begin{array}{l}1 \\
360\end{array}$ & $\begin{array}{l}1 \mathrm{~Hz} \\
120 \%\end{array}$ & $\begin{array}{l}\text { R DLPFC } \\
\text { Beam F3 method }\end{array}$ & $\begin{array}{l}\text { Figure-of-8 } \\
\text { ShamTMS coil }\end{array}$ & $\begin{array}{l}\text { VAS (cue-induced) * } \\
\text { GACS-desire factor, heart } \\
\text { rate, blood pressure }\end{array}$ & $\begin{array}{l}\text { No effect on craving } \\
\text { and other outcomes }\end{array}$ \\
\hline
\end{tabular}

10-20 syst, International 10-20 System; ACQ-NOW, Alcohol Craving Questionnaire; AN-BP, anorexia nervosa binge/purge type; AN-R, anorexia nervosa restrictive type; AUD, alcohol use disorder; AUQ, Alcohol Urge Questionnaire; BDI, Beck Depression Inventory; Bilat, bilateral; BMI, body mass index; BN, bulimia nervosa; CBT, cognitive behavioral therapy; CCT, controlled clinical trial; CGI, Clinical Global Impressions scale; CO, carbon monoxide; CRPS-SA, Comprehensive Psychopathological Rating Scale; Self-Rate; cTBS, continuous theta burst stimulation; DAT, dopamine transporter; DB, double blind; DDT, delay discounting task; DLPFC, dorsolateral prefrontal cortex; dTMS, deep transcranial magnetic stimulation; EDNOS-BN, eating disorder not otherwise specified-bulimic type; EEG, electroencephalogram; F, female; fALFF, amplitude of low frequency fluctuation; FCQ-S, Food Craving Questionnaire-State; FCT, food challenge task; fMRI, functional magnetic resonance imaging; FTCQ-12, French version of the 12-item Short Form of the Tobacco Craving Questionnaire; FTND, Fagerström Test for Nicotine Dependence; GACS, Gambling Craving Scale; HARS, Hamilton Anxiety Rating Scale; HC, healthy control; HDRS, Hamilton Depression Rating Scale; IIRTV, intraindividual reaction time variability; iTBS, intermittent theta burst stimulation; L, left; LS, Likert scale; M, male; MADRS, Montgomery-Asberg Depression Rating Scale; MPFC, medial prefrontal cortex; NRT, nicotine replacement therapy; NS, non-specified; NSc, numerical scale; OCDS, obsessive-compulsive drinking scale; OFC, orbitofrontal cortex (

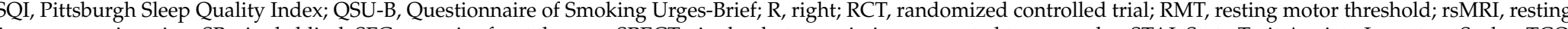
state magnetic resonance imaging, SB, single blind, ST, superior frontal gyrus; SPEC I, single photon emission computed tomography, STAI, State-Trait Anxiety Inventory Scale; sTCQ short version of the Tobacco Craving Questionnaire; TLFB, timeline followback interview; TLS, Ten-point Likert scale; U, urinary; VAS, visual analog scale. cTBS, 3 burst at 50 Hz applied at $5 \mathrm{~Hz}$; iTBS, 3 burst at $50 \mathrm{~Hz}, 2$ s every $10 \mathrm{s.}^{1}$ session frequency detailed only when different from usual daily protocol. ${ }^{2}$ time of measure detailed only when different from pre/post rTMS. ** same study. 


\section{References}

1. Koob, G.F.; Volkow, N.D. Neurobiology of addiction: A neurocircuitry analysis. Lancet Psychiatry 2016, 3, 760-773. [CrossRef]

2. American Psychiatric Association. Diagnostic and Statistical Manual of Mental Disorders, DSM Library; American Psychiatric Association: Washington, DC, USA, 2013.

3. World Health Organization. International Classification of Diseases for Mortality and Morbidity Statistics, 11th ed.; World Health Organization: Geneva, Switzerland, 2018; Available online: https://icd.who.int/browse11/1-m/en (accessed on 22 December 2021).

4. Gearhardt, A.N.; White, M.A.; Potenza, M.N. Binge eating disorder and food addiction. Curr. Drug Abus. Rev. 2011, 4, 201-207. [CrossRef] [PubMed]

5. Hadad, N.A.; Knackstedt, L.A. Addicted to palatable foods: Comparing the neurobiology of Bulimia Nervosa to that of drug addiction. Psychopharmacology 2014, 231, 1897-1912. [CrossRef] [PubMed]

6. Kalivas, P.W.; Volkow, N.D. The neural basis of addiction: A pathology of motivation and choice. Am. J. Psychiatry 2005, 162, 1403-1413. [CrossRef]

7. World Health Organization. Global Health Risks: Mortality and Burden of Disease Attributable to Selected Major Risks; World Health Organization: Geneva, Switzerland, 2009.

8. Chan, E.M.L.; Dowling, N.A.; Jackson, A.C.; Shek, D.T. Gambling related family coping and the impact of problem gambling on families in Hong Kong. Asian J. Gambl. Issues Public Health 2016, 6, 1-16. [CrossRef]

9. Smink, F.R.E.; van Hoeken, D.; Hoek, H.W. Epidemiology of eating disorders: Incidence, prevalence and mortality rates. Curr. Psychiatry Rep. 2012, 14, 406-414. [CrossRef]

10. Mitchell, J.E.; Myers, T.; Crosby, R.; O'Neill, G.; Carlisle, J.; Gerlach, S. Health care utilization in patients with eating disorders. Int J. Eat. Disord. 2009, 42, 571-574. [CrossRef]

11. Striegel-Moore, R.H.; DeBar, L.; Wilson, G.T.; Dickerson, J.; Rosselli, F.; Perrin, N.; Lynch, F.; Kraemer, H.C. Health services use in eating disorders. Psychol. Med. 2008, 38, 1465-1474. [CrossRef]

12. O'Brien, C.P. Review, Evidence-based treatments of addiction. Philos. Trans. R. Soc. Lond. B Biol. Sci. 2008, 363, 3277-3286. [CrossRef]

13. Amato, L.; Minozzi, S.; Davoli, M. Efficacy and safety of pharmacological interventions for the treatment of the Alcohol Withdrawal Syndrome. Cochrane Database Syst. Rev. 2011, 6, CD008537. [CrossRef]

14. Knapp, W.P.; Soares, B.G.O.; Farrel, M.; Lima, M.S. Psychosocial interventions for cocaine and psychostimulant amphetamines related disorders. Cochrane Database Syst. Rev. 2007, 3, CD003023. [CrossRef]

15. Stead, L.F.; Koilpillai, P.; Fanshawe, T.R.; Lancaster, T. Combined pharmacotherapy and behavioural interventions for smoking cessation. Cochrane Database Syst. Rev. 2016, 3, CD008286. [CrossRef] [PubMed]

16. Potenza, M.N.; Sofuoglu, M.; Carroll, K.M.; Rounsaville, B.J. Neuroscience of behavioral and pharmacological treatments for addictions. Neuron 2011, 69, 695-712. [CrossRef] [PubMed]

17. Achab, S.; Khazaal, Y. Psychopharmacological treatment in pathological gambling: A critical review. Curr. Pharm. Des. 2011, 17, 1389-1395. [CrossRef] [PubMed]

18. Bolt, D.M.; Piper, M.E.; Theobald, W.E.; Baker, T.B. Why two smoking cessation agents work better than one: Role of craving suppression. J. Consult. Clin. Psychol. 2012, 80, 54-65. [CrossRef]

19. Mariani, J.J.; Levin, F.R. Psychostimulant treatment of cocaine dependence. Psychiatr. Clin. N. Am. 2012, 35, 425-439. [CrossRef]

20. Müller, C.A.; Geisel, O.; Banas, R.; Heinz, A. Current pharmacological treatment approaches for alcohol dependence. Expert Opin. Pharmacother. 2014, 15, 471-481. [CrossRef]

21. O'Brien, C. Addiction and dependence in DSM-V. Addiction 2011, 106, 866-867. [CrossRef]

22. Skinner, M.D.; Aubin, H.-J. Craving's place in addiction theory: Contributions of the major models. Neurosci. Biobehav. Rev. 2010, 34, 606-623. [CrossRef]

23. Young, M.M.; Wohl, M.J.A. The Gambling Craving Scale: Psychometric validation and behavioral outcomes. Psychol. Addict. Behav. J. Soc. Psychol. Addict. Behav. 2009, 23, 512-522. [CrossRef]

24. Jansen, J.M.; Daams, J.G.; Koeter, M.W.J.; Veltman, D.J.; van den Brink, W.; Goudriaan, A.E. Effects of non-invasive neurostimulation on craving: A meta-analysis. Neurosci. Biobehav. Rev. 2013, 37, 2472-2480. [CrossRef]

25. Pelchat, M.L. Food addiction in humans. J. Nutr. 2009, 139, 620-622. [CrossRef]

26. Ashrafioun, L.; Rosenberg, H. Methods of assessing craving to gamble: A narrative review. Psychol. Addict. Behav. 2012, 26, 536-549. [CrossRef]

27. Rosenberg, H. Clinical and laboratory assessment of the subjective experience of drug craving. Clin. Psychol. Rev. 2009, 29, 519-534. [CrossRef]

28. Tiffany, S.T.; Wray, J.M. The clinical significance of drug craving: Tiffany \& Wray. Ann. N. Y. Acad. Sci. 2012, 1248, 1-17. [CrossRef]

29. Addolorato, G.; Abenavoli, L.; Leggio, L.; Gasbarrini, G. How many cravings? Pharmacological aspects of craving treatment in alcohol addiction: A review. Neuropsychobiology 2005, 51, 59-66. [CrossRef]

30. Oslin, D.W.; Cary, M.; Slaymaker, V.; Colleran, C.; Blow, F.C. Daily ratings measures of alcohol craving during an inpatient stay define subtypes of alcohol addiction that predict subsequent risk for resumption of drinking. Drug Alcohol Depend. 2009, 103, 131-136. [CrossRef] 
31. Paliwal, P.; Hyman, S.M.; Sinha, R. Craving predicts time to cocaine relapse: Further validation of the Now and Brief versions of the cocaine craving questionnaire. Drug Alcohol Depend. 2008, 93, 252-259. [CrossRef]

32. Sinha, R.; Garcia, M.; Paliwal, P.; Kreek, M.J.; Rounsaville, B.J. Stress-induced cocaine craving and hypothalamic-pituitary-adrenal responses are predictive of cocaine relapse outcomes. Arch. Gen. Psychiatry 2006, 63, 324-331. [CrossRef]

33. Hodgins, D.C.; el-Guebaly, N. Retrospective and prospective reports of precipitants to relapse in pathological gambling. J. Consult. Clin. Psychol. 2004, 72, 72-80. [CrossRef]

34. Jasinska, A.J.; Stein, E.A.; Kaiser, J.; Naumer, M.J.; Yalachkov, Y. Factors modulating neural reactivity to drug cues in addiction: A survey of human neuroimaging studies. Neurosci. Biobehav. Rev. 2014, 38, 1-16. [CrossRef] [PubMed]

35. Kober, H.; Lacadie, C.M.; Wexler, B.E.; Malison, R.T.; Sinha, R.; Potenza, M.N. Brain Activity During Cocaine Craving and Gambling Urges: An fMRI Study. Neuropsychopharmacol. Off. Publ. Am. Coll. Neuropsychopharmacol. 2016, 41, 628-637. [CrossRef] [PubMed]

36. Lee, J.-H.; Lim, Y.; Wiederhold, B.K.; Graham, S.J. A functional magnetic resonance imaging (FMRI) study of cue-induced smoking craving in virtual environments. Appl. Psychophysiol. Biofeedback 2005, 30, 195-204. [CrossRef] [PubMed]

37. Limbrick-Oldfield, E.H.; Mick, I.; Cocks, R.E.; McGonigle, J.; Sharman, S.P.; Goldstone, A.P.; Stokes, P.R.A.; Waldman, A.; Erritzoe, D.; Bowden-Jones, H.; et al. Neural substrates of cue reactivity and craving in gambling disorder. Transl. Psychiatry 2017, 7, e992. [CrossRef]

38. Volkow, N.D.; Wang, G.-J.; Ma, Y.; Fowler, J.S.; Wong, C.; Ding, Y.-S.; Hitzemann, R.; Swanson, J.M.; Kalivas, P. Activation of orbital and medial prefrontal cortex by methylphenidate in cocaine-addicted subjects but not in controls: Relevance to addiction. J. Neurosci. Off. J. Soc. Neurosci. 2005, 25, 3932-3939. [CrossRef]

39. Goldstein, R.Z.; Volkow, N.D. Drug addiction and its underlying neurobiological basis: Neuroimaging evidence for the involvement of the frontal cortex. Am. J. Psychiatry 2002, 159, 1642-1652. [CrossRef]

40. Koob, G.F.; Le Moal, M. Drug abuse: Hedonic homeostatic dysregulation. Science 1997, 278, 52-58. [CrossRef]

41. Berridge, K.C. The debate over dopamine's role in reward: The case for incentive salience. Psychopharmacology 2007, 191, 391-431. [CrossRef]

42. Volkow, N.D.; Fowler, J.S.; Wang, G.J.; Baler, R.; Telang, F. Imaging dopamine's role in drug abuse and addiction. Neuropharmacology 2009, 56 (Suppl. S1), 3-8. [CrossRef]

43. Bestmann, S.; Baudewig, J.; Siebner, H.R.; Rothwell, J.C.; Frahm, J. BOLD MRI responses to repetitive TMS over human dorsal premotor cortex. NeuroImage 2005, 28, 22-29. [CrossRef]

44. Barr, M.S.; Farzan, F.; Rusjan, P.M.; Chen, R.; Fitzgerald, P.B.; Daskalakis, Z.J. Potentiation of Gamma Oscillatory Activity through Repetitive Transcranial Magnetic Stimulation of the Dorsolateral Prefrontal Cortex. Neuropsychopharmacology 2009, 34, $2359-2367$. [CrossRef] [PubMed]

45. Cho, S.S.; Strafella, A.P. rTMS of the Left Dorsolateral Prefrontal Cortex Modulates Dopamine Release in the Ipsilateral Anterior Cingulate Cortex and Orbitofrontal Cortex. PLoS ONE 2009, 4, e6725. [CrossRef] [PubMed]

46. Strafella, A.P.; Paus, T.; Fraraccio, M.; Dagher, A. Striatal dopamine release induced by repetitive transcranial magnetic stimulation of the human motor cortex. Brain 2003, 126, 2609-2615. [CrossRef] [PubMed]

47. Bellamoli, E.; Manganotti, P.; Schwartz, R.P.; Rimondo, C.; Gomma, M.; Serpelloni, G. rTMS in the treatment of drug addiction: An update about human studies. Behav. Neurol. 2014, 2014, 815215. [CrossRef]

48. Fox, P.; Ingham, R.; George, M.S.; Mayberg, H.; Ingham, J.; Roby, J.; Martin, C.; Jerabek, P. Imaging human intra-cerebral connectivity by PET during TMS. Neuroreport 1997, 8, 2787-2791. [CrossRef]

49. Gorelick, D.A.; Zangen, A.; George, M.S. Transcranial magnetic stimulation in the treatment of substance addiction. Ann. N. Y. Acad. Sci. 2014, 1327, 79-93. [CrossRef]

50. Roth, Y.; Zangen, A.; Hallett, M. A coil design for transcranial magnetic stimulation of deep brain regions. J. Clin. Neurophysiol. Off. Publ. Am. Electroencephalogr. Soc. 2002, 19, 361-370. [CrossRef]

51. Zangen, A.; Roth, Y.; Voller, B.; Hallett, M. Transcranial magnetic stimulation of deep brain regions: Evidence for efficacy of the H-coil. Clin. Neurophysiol. Off. J. Int. Fed. Clin. Neurophysiol. 2005, 116, 775-779. [CrossRef]

52. Levkovitz, Y.; Harel, E.V.; Roth, Y.; Braw, Y.; Most, D.; Katz, L.N.; Sheer, A.; Gersner, R.; Zangen, A. Deep transcranial magnetic stimulation over the prefrontal cortex: Evaluation of antidepressant and cognitive effects in depressive patients. Brain Stimulat. 2009, 2, 188-200. [CrossRef]

53. Pascual-Leone, A.; Valls-Solé, J.; Wassermann, E.M.; Hallett, M. Responses to rapid-rate transcranial magnetic stimulation of the human motor cortex. Brain J. Neurol. 1994, 117 Pt 4, 847-858. [CrossRef]

54. Huang, Y.-Z.; Edwards, M.J.; Rounis, E.; Bhatia, K.P.; Rothwell, J.C. Theta burst stimulation of the human motor cortex. Neuron 2005, 45, 201-206. [CrossRef] [PubMed]

55. Lefaucheur, J.-P.; André-Obadia, N.; Antal, A.; Ayache, S.S.; Baeken, C.; Benninger, D.H.; Cantello, R.M.; Cincotta, M.; de Carvalho, M.; De Ridder, D.; et al. Evidence-based guidelines on the therapeutic use of repetitive transcranial magnetic stimulation (rTMS). Clin. Neurophysiol. Off. J. Int. Fed. Clin. Neurophysiol. 2014, 125, 2150-2206. [CrossRef] [PubMed]

56. Nitsche, M.A.; Paulus, W. Sustained Excitability Elevations Induced by Transcranial DC Motor Cortex Stimulation in Humans. Neurology 2001, 57, 1899-1901. [CrossRef] [PubMed] 
57. Song, S.; Zilverstand, A.; Gui, W.; Li, H.-J.; Zhou, X. Effects of single-session versus multi-session non-invasive brain stimulation on craving and consumption in individuals with drug addiction, eating disorders or obesity: A meta-analysis. Brain Stimulat. 2019, 12, 606-618. [CrossRef]

58. Carr, D.B.; Sesack, S.R. Projections from the rat prefrontal cortex to the ventral tegmental area: Target specificity in the synaptic associations with mesoaccumbens and mesocortical neurons. J. Neurosci. Off. J. Soc. Neurosci. 2000, 20, 3864-3873. [CrossRef]

59. Diana, M. The dopamine hypothesis of drug addiction and its potential therapeutic value. Front. Psychiatry 2011, 2, 64. [CrossRef]

60. Pettorruso, M.; di Giannantonio, M.; De Risio, L.; Martinotti, G.; Koob, G.F. A Light in the Darkness: Repetitive Transcranial Magnetic Stimulation (rTMS) to Treat the Hedonic Dysregulation of Addiction. J. Addict. Med. 2020, 14, 272-274. [CrossRef]

61. Moccia, L.; Pettorruso, M.; De Crescenzo, F.; De Risio, L.; di Nuzzo, L.; Martinotti, G.; Bifone, A.; Janiri, L.; Di Nicola, M. Neural correlates of cognitive control in gambling disorder: A systematic review of fMRI studies. Neurosci. Biobehav. Rev. 2017, 78, 104-116. [CrossRef]

62. Garavan, H.; Hester, R. The role of cognitive control in cocaine dependence. Neuropsychol. Rev. 2007, 17, 337-345. [CrossRef]

63. van Holst, R.J.; Schilt, T. Drug-related decrease in neuropsychological functions of abstinent drug users. Curr. Drug Abus. Rev. 2011, 4, 42-56. [CrossRef]

64. Kearney-Ramos, T.E.; Dowdle, L.T.; Lench, D.H.; Mithoefer, O.J.; Devries, W.H.; George, M.S.; Anton, R.F.; Hanlon, C.A. Transdiagnostic Effects of Ventromedial Prefrontal Cortex Transcranial Magnetic Stimulation on Cue Reactivity. Biol. Psychiatry Cogn. Neurosci. Neuroimaging 2018, 3, 599-609. [CrossRef] [PubMed]

65. Enokibara, M.; Trevizol, A.; Shiozawa, P.; Cordeiro, Q. Establishing an effective TMS protocol for craving in substance addiction: Is it possible? Am. J. Addict. Am. Acad. Psychiatr. Alcohol. Addict. 2016, 25, 28-30. [CrossRef] [PubMed]

66. Lowe, C.J.; Vincent, C.; Hall, P.A. Effects of Noninvasive Brain Stimulation on Food Cravings and Consumption: A Meta-Analytic Review. Psychosom. Med. 2017, 79, 2-13. [CrossRef] [PubMed]

67. Ma, T.; Sun, Y.; Ku, Y. Effects of Non-invasive Brain Stimulation on Stimulant Craving in Users of Cocaine, Amphetamine, or Methamphetamine: A Systematic Review and Meta-Analysis. Front. Neurosci. 2019, 13, 1095. [CrossRef]

68. Maiti, R.; Mishra, B.R.; Hota, D. Effect of High-Frequency Transcranial Magnetic Stimulation on Craving in Substance Use Disorder: A Meta-Analysis. J. Neuropsychiatry Clin. Neurosci. 2016, 29, 160-171. [CrossRef]

69. Mostafavi, S.-A.; Khaleghi, A.; Mohammadi, M.R. Noninvasive brain stimulation in alcohol craving: A systematic review and meta-analysis. Prog. Neuropsychopharmacol. Biol. Psychiatry 2020, 101, 109938. [CrossRef]

70. Zhang, J.J.Q.; Fong, K.N.K.; Ouyang, R.-G.; Siu, A.M.H.; Kranz, G.S. Effects of repetitive transcranial magnetic stimulation (rTMS) on craving and substance consumption in patients with substance dependence: A systematic review and meta-analysis. Addict. Abingdon Engl. 2019, 114, 2137-2149. [CrossRef]

71. Grall-Bronnec, M.; Sauvaget, A. The use of repetitive transcranial magnetic stimulation for modulating craving and addictive behaviours: A critical literature review of efficacy, technical and methodological considerations. Neurosci. Biobehav. Rev. 2014, 47, 592-613. [CrossRef]

72. Moher, D.; Liberati, A.; Tetzlaff, J.; Altman, D.G.; The PRISMA Group. Preferred reporting items for systematic reviews and meta-analyses: The PRISMA statement. PLoS Med. 2009, 6, e1000097. [CrossRef]

73. Higgins, J.P.T.; Thomas, J.; Chandler, J.; Cumpston, M.; Li, T.; Page, M.J.; Welch, V.A. (Eds.) Cochrane Handbook for Systematic Reviews of Interventions Version 6.1 (Updated September 2020); Cochrane: London, UK, 2020.

74. Hone-Blanchet, A.; Ciraulo, D.A.; Pascual-Leone, A.; Fecteau, S. Noninvasive brain stimulation to suppress craving in substance use disorders: Review of human evidence and methodological considerations for future work. Neurosci. Biobehav. Rev. 2015, 59, 184-200. [CrossRef]

75. DerSimonian, R.; Laird, N. Meta-analysis in clinical trials revisited, Contemp. Clin. Trials 2015, 45, 139-145. [CrossRef]

76. Hozo, S.P.; Djulbegovic, B.; Hozo, I. Estimating the mean and variance from the median, range, and the size of a sample. BMC Med. Res. Methodol. 2005, 5, 13. [CrossRef] [PubMed]

77. Borenstein, M.; Hedges, L.V.; Higgins, J.P.T.; Rothstein, H.R. A basic introduction to fixed-effect and random-effects models for meta-analysis. Res. Synth. Methods 2010, 1, 97-111. [CrossRef] [PubMed]

78. Higgins, J.P.T.; Thompson, S.G.; Deeks, J.J.; Altman, D.G. Measuring inconsistency in meta-analyses. BMJ 2003, 327, 557-560. [CrossRef]

79. Curtin, F. Meta-analysis combining parallel and cross-over trials with random effects. Res. Synth. Methods 2017, 8, 263-274. [CrossRef]

80. Hanlon, C.A.; Dowdle, L.T.; Austelle, C.W.; DeVries, W.; Mithoefer, O.; Badran, B.W.; George, M.S. What goes up, can come down: Novel brain stimulation paradigms may attenuate craving and craving-related neural circuitry in substance dependent individuals. Brain Res. 2015, 1628, 199-209. [CrossRef]

81. Höppner, J.; Broese, T.; Wendler, L.; Berger, C.; Thome, J. Repetitive transcranial magnetic stimulation (rTMS) for treatment of alcohol dependence. World J. Biol. Psychiatry 2011, 12, 57-62. [CrossRef]

82. Jansen, J.M.; van den Heuvel, O.A.; van der Werf, Y.D.; de Wit, S.J.; Veltman, D.J.; van den Brink, W.; Goudriaan, A.E. The Effect of High-Frequency Repetitive Transcranial Magnetic Stimulation on Emotion Processing, Reappraisal, and Craving in Alcohol Use Disorder Patients and Healthy Controls: A Functional Magnetic Resonance Imaging Study. Front. Psychiatry 2019, 10, 272. [CrossRef] 
83. Li, X.; Malcolm, R.J.; Huebner, K.; Hanlon, C.A.; Taylor, J.J.; Brady, K.T.; George, M.S.; See, R.E. Low frequency repetitive transcranial magnetic stimulation of the left dorsolateral prefrontal cortex transiently increases cue-induced craving for methamphetamine: A preliminary study. Drug Alcohol Depend. 2013, 133, 641-646. [CrossRef]

84. Liang, Y.; Wang, L.; Yuan, T.-F. Targeting Withdrawal Symptoms in Men Addicted to Methamphetamine with Transcranial Magnetic Stimulation: A Randomized Clinical Trial. JAMA Psychiatry 2018, 75, 1199-1201. [CrossRef]

85. Liu, Q.; Shen, Y.; Cao, X.; Li, Y.; Chen, Y.; Yang, W.; Yuan, T.-F. Either at left or right, both high and low frequency rTMS of dorsolateral prefrontal cortex decreases cue induced craving for methamphetamine. Am. J. Addict. 2017, 26, 776-779. [CrossRef]

86. Perini, I.; Kämpe, R.; Arlestig, T.; Karlsson, H.; Löfberg, A.; Pietrzak, M.; Zangen, A.; Heilig, M. Repetitive transcranial magnetic stimulation targeting the insular cortex for reduction of heavy drinking in treatment-seeking alcohol-dependent subjects: A randomized controlled trial. Neuropsychopharmacol. Off. Publ. Am. Coll. Neuropsychopharmacol. 2019, 19, 0565-7. [CrossRef]

87. Pripfl, J.; Tomova, L.; Riecansky, I.; Lamm, C. Transcranial Magnetic Stimulation of the Left Dorsolateral Prefrontal Cortex Decreases Cue-induced Nicotine Craving and EEG Delta Power. Brain Stimulat. 2014, 7, 226-233. [CrossRef]

88. Rose, J.E.; McClernon, F.J.; Froeliger, B.; Behm, F.M.; Preud'homme, X.; Krystal, A.D. Repetitive transcranial magnetic stimulation of the superior frontal gyrus modulates craving for cigarettes. Biol. Psychiatry 2011, 70, 794-799. [CrossRef]

89. Sauvaget, A.; Bulteau, S.; Guilleux, A.; Leboucher, J.; Pichot, A.; Valrivière, P.; Vanelle, J.-M.; Sébille-Rivain, V.; Grall-Bronnec, M. Both active and sham low-frequency rTMS single sessions over the right DLPFC decrease cue-induced cravings among pathological gamblers seeking treatment: A randomized, double-blind, sham-controlled crossover trial. J. Behav. Addict. 2018, 7, 126-136. [CrossRef]

90. Yuan, J.; Liu, W.; Liang, Q.; Cao, X.; Lucas, M.V.; Yuan, T.-F. Effect of Low-Frequency Repetitive Transcranial Magnetic Stimulation on Impulse Inhibition in Abstinent Patients with Methamphetamine Addiction: A Randomized Clinical Trial. JAMA Netw. Open 2020, 3, e200910. [CrossRef]

91. Addolorato, G.; Antonelli, M.; Cocciolillo, F.; Vassallo, G.A.; Tarli, C.; Sestito, L.; Mirijello, A.; Ferrulli, A.; Pizzuto, D.A.; Camardese, G.; et al. Deep Transcranial Magnetic Stimulation of the Dorsolateral Prefrontal Cortex in Alcohol Use Disorder Patients: Effects on Dopamine Transporter Availability and Alcohol Intake. Eur. Neuropsychopharmacol. 2017, $27,450-461$. [CrossRef]

92. Ceccanti, M.; Inghilleri, M.; Attilia, M.L.; Raccah, R.; Fiore, M.; Zangen, A.; Ceccanti, M. Deep TMS on alcoholics: Effects on cortisolemia and dopamine pathway modulation. A pilot study. Can. J. Physiol. Pharmacol. 2015, 93, 283-290. [CrossRef]

93. Amiaz, R.; Levy, D.; Vainiger, D.; Grunhaus, L.; Zangen, A. Repeated high-frequency transcranial magnetic stimulation over the dorsolateral prefrontal cortex reduces cigarette craving and consumption. Addiction 2009, 104, 653-660. [CrossRef]

94. Del Felice, A.; Bellamoli, E.; Formaggio, E.; Manganotti, P.; Masiero, S.; Cuoghi, G.; Rimondo, C.; Genetti, B.; Sperotto, M.; Corso, F.; et al. Neurophysiological, psychological and behavioural correlates of rTMS treatment in alcohol dependence. Drug Alcohol Depend. 2016, 158, 147-153. [CrossRef]

95. Dieler, A.C.; Dresler, T.; Joachim, K.; Deckert, J.; Herrmann, M.J.; Fallgatter, A.J. Can intermittent theta burst stimulation as add-on to psychotherapy improve nicotine abstinence? Results from a pilot study. Eur. Addict. Res. 2014, 20, 248-253. [CrossRef]

96. Gay, A.; Jaussent, I.; Sigaud, T.; Billard, S.; Attal, J.; Seneque, M.; Galusca, B.; Van Den Eynde, F.; Massoubre, C.; Courtet, P.; et al. A Lack of Clinical Effect of High-frequency rTMS to Dorsolateral Prefrontal Cortex on Bulimic Symptoms: A Randomised, Double-blind Trial. Eur. Eat. Disord. Rev. J. Eat. Disord. Assoc. 2016, 24, 474-481. [CrossRef]

97. Gay, A.; Boutet, C.; Sigaud, T.; Kamgoue, A.; Sevos, J.; Brunelin, J.; Massoubre, C. A single session of repetitive transcranial magnetic stimulation of the prefrontal cortex reduces cue-induced craving in patients with gambling disorder. Eur. Psychiatry J. Assoc. Eur. Psychiatr. 2017, 41, 68-74. [CrossRef]

98. Hanlon, C.; Dowdle, L.; Anton, R.; George, M. Ventral medial prefrontal cortex theta burst stimulation decreases salience network activity in cocaine users and alcohol users. Brain Stimul. Basic Transl. Clin. Res. Neuromodul. 2017, 10, 479. [CrossRef]

99. Herremans, S.C.; Baeken, C.; Vanderbruggen, N.; Vanderhasselt, M.A.; Zeeuws, D.; Santermans, L.; De Raedt, R. No influence of one right-sided prefrontal HF-rTMS session on alcohol craving in recently detoxified alcohol-dependent patients: Results of a naturalistic study. Drug Alcohol Depend. 2012, 120, 209-213. [CrossRef]

100. Herremans, S.C.; Vanderhasselt, M.-A.; De Raedt, R.; Baeken, C. Reduced Intra-individual Reaction Time Variability During a Go-NoGo Task in Detoxified Alcohol-Dependent Patients After One Right-Sided Dorsolateral Prefrontal HF-rTMS Session. Alcohol Alcohol. 2013, 48, 552-557. [CrossRef]

101. Herremans, S.C.; De Raedt, R.; Van Schuerbeek, P.; Marinazzo, D.; Matthys, F.; De Mey, J.; Baeken, C. Accelerated HF-rTMS Protocol has a Rate-Dependent Effect on dACC Activation in Alcohol-Dependent Patients: An Open-Label Feasibility Study. Alcohol. Clin. Exp. Res. 2016, 40, 196-205. [CrossRef]

102. Johann, M.; Wiegand, R.; Kharraz, A.; Bobbe, G.; Sommer, G.; Hajak, G.; Wodarz, N.; Eichhammer, P. Transcranial magnetic stimulation for nicotine dependence. Psychiatr. Prax. 2003, 30 (Suppl. S2), S129-S131.

103. Li, X.; Hartwell, K.J.; Owens, M.; LeMatty, T.; Borckardt, J.J.; Hanlon, C.A.; Brady, K.T.; George, M.S. Repetitive Transcranial Magnetic Stimulation of the Dorsolateral Prefrontal Cortex Reduces Nicotine Cue Craving. Biol. Psychiatry 2013, 73, 714-720. [CrossRef]

104. Li, X.; Du, L.; Sahlem, G.L.; Badran, B.W.; Henderson, S.; George, M.S. Repetitive transcranial magnetic stimulation (rTMS) of the dorsolateral prefrontal cortex reduces resting-state insula activity and modulates functional connectivity of the orbitofrontal cortex in cigarette smokers. Drug Alcohol Depend. 2017, 174, 98-105. [CrossRef] 
105. McClelland, J.; Kekic, M.; Bozhilova, N.; Nestler, S.; Dew, T.; Van den Eynde, F.; David, A.S.; Rubia, K.; Campbell, I.C.; Schmidt, U. A Randomised Controlled Trial of Neuronavigated Repetitive Transcranial Magnetic Stimulation (rTMS) in Anorexia Nervosa. PLoS ONE 2016, 11, e0148606. [CrossRef] [PubMed]

106. Mishra, B.R.; Nizamie, S.H.; Das, B.; Praharaj, S.K. Efficacy of repetitive transcranial magnetic stimulation in alcohol dependence: A sham-controlled study: Efficacy of rTMS in alcohol dependence. Addiction 2010, 105, 49-55. [CrossRef] [PubMed]

107. Sahlem, G.L.; Baker, N.L.; George, M.S.; Malcolm, R.J.; McRae-Clark, A.L. Repetitive transcranial magnetic stimulation (rTMS) administration to heavy cannabis users. Am. J. Drug Alcohol Abus. 2018, 44, 47-55. [CrossRef] [PubMed]

108. Shen, Y.; Cao, X.; Tan, T.; Shan, C.; Wang, Y.; Pan, J.; He, H.; Yuan, T.-F. 10-Hz Repetitive Transcranial Magnetic Stimulation of the Left Dorsolateral Prefrontal Cortex Reduces Heroin Cue Craving in Long-Term Addicts. Biol. Psychiatry 2016, 80, e13-e14. [CrossRef] [PubMed]

109. Su, H.; Zhong, N.; Gan, H.; Wang, J.; Han, H.; Chen, T.; Li, X.; Ruan, X.; Zhu, Y.; Jiang, H.; et al. High frequency repetitive transcranial magnetic stimulation of the left dorsolateral prefrontal cortex for methamphetamine use disorders: A randomised clinical trial. Drug Alcohol Depend. 2017, 175, 84-91. [CrossRef]

110. Su, H.; Chen, T.; Jiang, H.; Zhong, N.; Du, J.; Xiao, K.; Xu, D.; Song, W.; Zhao, M. Intermittent theta burst transcranial magnetic stimulation for methamphetamine addiction: A randomized clinical trial. Eur. Neuropsychopharmacol. J. Eur. Coll. Neuropsychopharmacol. 2020, 31, 158-161. [CrossRef]

111. Trojak, B.; Meille, V.; Achab, S.; Lalanne, L.; Poquet, H.; Ponavoy, E.; Blaise, E.; Bonin, B.; Chauvet-Gelinier, J.-C. Transcranial Magnetic Stimulation Combined with Nicotine Replacement Therapy for Smoking Cessation: A Randomized Controlled Trial. Brain Stimulat. 2015, 8, 1168-1174. [CrossRef]

112. Van den Eynde, F.; Claudino, A.M.; Mogg, A.; Horrell, L.; Stahl, D.; Ribeiro, W.; Uher, R.; Campbell, I.; Schmidt, U. Repetitive transcranial magnetic stimulation reduces cue-induced food craving in bulimic disorders. Biol. Psychiatry 2010, 67, 793-795. [CrossRef]

113. Zack, M.; Cho, S.S.; Parlee, J.; Jacobs, M.; Li, C.; Boileau, I.; Strafella, A. Effects of High Frequency Repeated Transcranial Magnetic Stimulation and Continuous Theta Burst Stimulation on Gambling Reinforcement, Delay Discounting, and Stroop Interference in Men with Pathological Gambling. Brain Stimulat. 2016, 9, 867-875. [CrossRef]

114. Meule, A.; Gearhardt, A. Food Addiction in the Light of DSM-5. Nutrients 2014, 6, 3653-3671. [CrossRef]

115. Barth, K.S.; Rydin-Gray, S.; Kose, S.; Borckardt, J.J.; O’Neil, P.M.; Shaw, D.; Madan, A.; Budak, A.; George, M.S. Food cravings and the effects of left prefrontal repetitive transcranial magnetic stimulation using an improved sham condition. Front. Psychiatry 2011, 2, 9. [CrossRef] [PubMed]

116. Uher, R.; Yoganathan, D.; Mogg, A.; Eranti, S.V.; Treasure, J.; Campbell, I.C.; McLoughlin, D.M.; Schmidt, U. Effect of left prefrontal repetitive transcranial magnetic stimulation on food craving. Biol. Psychiatry 2005, 58, 840-842. [CrossRef] [PubMed]

117. Badiani, A.; Belin, D.; Epstein, D.; Calu, D.; Shaham, Y. Opiate versus psychostimulant addiction: The differences do matter. Nat. Rev. Neurosci. 2011, 12, 685-700. [CrossRef] [PubMed]

118. Gomis-Vicent, E.; Thoma, V.; Turner, J.J.D.; Hill, K.P.; Pascual-Leone, A. Review: Non-Invasive Brain Stimulation in Behavioral Addictions: Insights from Direct Comparisons with Substance Use Disorders. Am. J. Addict. 2019, 28, 431-454. [CrossRef]

119. Harel, M.; Perini, I.; Kämpe, R.; Alyagon, U.; Shalev, H.; Besser, I.; Sommer, W.H.; Heilig, M.; Zangen, A. Repetitive Transcranial Magnetic Stimulation in Alcohol Dependence: A Randomized, Double-Blind, Sham-Controlled Proof-of-Concept Trial Targeting the Medial Prefrontal and Anterior Cingulate Cortices. Biol. Psychiatry 2021, in press. [CrossRef]

120. Flaudias, V.; Heeren, A.; Brousse, G.; Maurage, P. Toward a Triadic Approach to Craving in Addictive Disorders: The Metacognitive Hub Model. Harv. Rev. Psychiatry 2019, 27, 326-331. [CrossRef]

121. Trojak, B.; Meille, V.; Chauvet-Gelinier, J.-C.; Bonin, B. Further evidence of the usefulness of MRI-based neuronavigation for the treatment of depression by rTMS. J. Neuropsychiatry Clin. Neurosci. 2011, 23, E30-E31. [CrossRef]

122. Valero-Cabré, A.; Pascual-Leone, A.; Rushmore, R.J. Cumulative sessions of repetitive transcranial magnetic stimulation (rTMS) build up facilitation to subsequent TMS-mediated behavioural disruptions. Eur. J. Neurosci. 2008, 27, 765-774. [CrossRef]

123. Rachid, F. Maintenance repetitive transcranial magnetic stimulation (rTMS) for relapse prevention in with depression: A review. Psychiatry Res. 2018, 262, 363-372. [CrossRef]

124. Zangen, A.; Moshe, H.; Martinez, D.; Barnea-Ygael, N.; Vapnik, T.; Bystritsky, A.; Duffy, W.; Toder, D.; Casuto, L.; Grosz, M.L.; et al. Repetitive Transcranial Magnetic Stimulation for Smoking Cessation: A Pivotal Multicenter Double-blind Randomized Controlled Trial. World Psychiatry 2021, 20, 397-404. [CrossRef]

125. Madeo, G.; Terraneo, A.; Cardullo, S.; Gómez Pérez, L.J.; Cellini, N.; Sarlo, M.; Bonci, A.; Gallimberti, L. Long-Term Outcome of Repetitive Transcranial Magnetic Stimulation in a Large Cohort of Patients with Cocaine-Use Disorder: An Observational Study. Front. Psychiatry 2020, 11, 158. [CrossRef] [PubMed] 